\title{
Metabolic and production profiles of dairy cows in response to decreased nutrient density to increase physiological imbalance at different stages of lactation
}

\author{
V. Bjerre-Harpøth, ${ }^{\star}$ N. C. Friggens, ${ }^{*} \dagger \ddagger$ V. M. Thorup, ${ }^{*}$ T. Larsen, ${ }^{\star}$ B. M. Damgaard, ${ }^{\star}$ K. L. Ingvartsen, ${ }^{*}$ \\ and K. M. Moyes ${ }^{* 1}$ \\ ${ }^{*}$ Department of Animal Science, Faculty of Science and Technology, Aarhus University, 8830 Tjele, Denmark \\ †INRA UMR 791 Modélisation Systémique Appliquée aux Ruminants, 16 rue Claude Bernard, 75231 Paris, France \\ ¥AgroParisTech UMR 791 Modélisation Systémique Appliquée aux Ruminants, 16 rue Claude Bernard, 75231 Paris, France
}

\begin{abstract}
Physiological imbalance (PI) is a situation in which physiological parameters deviate from the normal, and cows consequently have an increased risk of developing production diseases and reduced production or reproduction. Our objectives were to (1) determine the effect of stage of lactation and milk yield on metabolic and production responses of cows during a nutrient restriction period to experimentally increase PI; (2) identify major metabolites that relate to degree of PI; and (3) identify potential biomarkers in milk for on-farm detection of PI throughout lactation. Forty-seven Holstein cows in early $[\mathrm{n}=14 ; 49 \pm 22 \mathrm{~d}$ in milk (DIM); parity $=1.6 \pm 0.5]$, mid $(\mathrm{n}=15 ; 159 \pm 39$ DIM; parity $=1.5$ $\pm 0.5)$, and late $(\mathrm{n}=18 ; 273 \pm 3$ DIM; parity $=1.3 \pm$ $0.5)$ lactation were used. Prior to restriction, all cows were fed the same total mixed ration ad libitum. All cows were then nutrient restricted for $4 \mathrm{~d}$ by supplementing the ration with $60 \%$ wheat straw to induce PI. After restriction, cows returned to full feed. Daily milk yield was recorded and composite milk samples were analyzed for fat, protein, lactose, citrate, somatic cells, uric acid, alkaline phosphatase, $\beta$-hydroxybutyrate (BHBA), and milk urea nitrogen. Blood was collected daily and analyzed for metabolites: nonesterified fatty acids (NEFA), BHBA, glucose, plasma urea nitrogen, and insulin. The revised quantitative insulin sensitivity check index (RQUICKI) was calculated for each cow. Liver biopsies collected before and during restriction were analyzed for triglycerides, glycogen, phospholipids, glucose, and total lipid content. A generalized linear mixed model was used to determine the effect of stage of lactation on responses during restriction. Regression analyses were used to examine the effect of prerestriction levels on changes during restriction. Similar
\end{abstract}

Received April 6, 2011.

Accepted December 28, 2011

${ }^{1}$ Corresponding author: Kasey.Moyes@agrsci.dk decreases in milk yield among groups indicate that the capacity of individual responses is dependent on milk yield but the coping strategies used are dependent on stage of lactation. Milk yield was a better predictor of feed intake than DIM. Plasma glucose decreased for all cows, and cows in early lactation had increased plasma BHBA, whereas cows in later lactation had increased NEFA during restriction. Milk citrate had the greatest increase (58\%) during restriction for all cows. Results reported here identified metabolites (i.e., glucose, NEFA, BHBA, cholesterol) as predictors of PI and identified milk citrate as a promising biomarker for PI on farm.

Key words: cow, stage of lactation, physiological imbalance

\section{INTRODUCTION}

The dairy industry is currently undergoing rapid structural developments, in which herd size continues to increase along with the number of animals being managed per person. Regardless of improvements in genetic selection programs and management, general disease incidence is still substantial. The development of in-line and real-time automatic monitoring systems (e.g., Herd Navigator, Lattec I/S, Hillerød, Denmark) help farm staff oversee large numbers of animals with the aim of providing early detection systems to prevent and reduce the incidence of disease while optimizing performance. Production diseases and reproductive issues are serious problems on most dairy farms and it has been hypothesized that physiological imbalance (PI) in individual cows is a major cause for certain diseases during lactation (Ingvartsen and Friggens, 2005). Physiological imbalance is defined here as a situation in which physiological parameters (reflecting the function of the digestive tract, metabolic state, and immune state) deviate from the normal; and consequently, these cows have an increased risk of developing production diseases (clinical or subclinical), reduced production 
and/or reproduction (Ingvartsen and Friggens, 2005; Ingvartsen, 2006; Moyes et al., 2010). For example, cows experiencing a more severe or extended period of negative energy balance than normally observed during early lactation that in turn increases risk of disease would be classified as being in a period of PI. In addition, PI can occur throughout lactation as a secondary health problem when feed intake is significantly reduced; that is, "off-feed" situations (Vasquez-Añon et al., 1994; Ingvartsen and Andersen, 2000).

Currently, several indicators are being used on-farm to identify cows with metabolic diseases; for example, the use of milk BHBA to predict clinical ketosis (Nielsen et al., 2005) and liver triacylglycerol (TAG) content to identify cows with hepatic lipidosis (Starke et al., 2011). However, these systems have so far generally been based on just one analyte, are not easily accessible on-farm (i.e., liver TAG content), and only predict disease after subclinical or clinical signs have developed. Hence, the generation of a system for predicting PI would lead to proactive management to combat PI and prevent the development of subclinical or clinical disease, thereby improving animal health and welfare and economic outcome for the farmer.

The development of such a system is dependent on the degree of biological understanding of PI and technical and sensor capability. Although a large body of work extending over decades has demonstrated the metabolic consequences of undernutrition (Mills et al., 1986; Radcliff et al., 2006; Guinard-Flament et al., 2007), relatively little information exists to permit the quantification of these effects and especially the magnitude of these effects by stage of lactation. In turn, this will allow us to predict the size of metabolic perturbations for in-line and real-time early warning systems according to stage of lactation and milk production and component level. Therefore, our objectives were to (1) determine the effect of milk production level and stage of lactation on production and metabolic responses of cows during a nutrient restriction period to experimentally increase PI and off-feed situations; (2) identify major metabolites that relate to degree of PI for their use in an index to predict PI and off-feed situations throughout lactation; and (3) identify potential biomarkers currently available in milk for PI and offfeed situations throughout lactation for early warning systems that will help farm staff oversee large numbers of animals and identify at-risk animals.

\section{MATERIALS AND METHODS}

All procedures involving animals were evaluated and approved by the Danish Animal Experiments Inspectorate and complied with the Danish Laws concern- ing animal experimentation and care of experimental animals.

\section{Animals and Housing}

Forty-seven healthy Holstein dairy cows in early (n $=14 ; 49 \pm 22 \mathrm{DIM})$, mid $(\mathrm{n}=15 ; 159 \pm 39 \mathrm{DIM})$, and late $(\mathrm{n}=18 ; 273 \pm 33 \mathrm{DIM})$ lactation from the resident herd at the Danish Cattle Research Centre (Tjele, Denmark) were used as experimental animals. Of these, 26 cows were primiparous and 21 cows were multiparous ( $\geq$ second lactation; ranging from parity $2-5$ ) with 5 , 8 , and 13 primiparous and 9,7 , and 5 multiparous cows in early, mid, and late lactation, respectively. Data were collected throughout November 2008. Cows were housed in one group in a loose housing system containing individual automatic feeding stations (Roughage Intake System, Insentec BV, Marknesse, the Netherlands) and milked automatically by an automatic milking system (VMS; Voluntary Milking System, DeLaval, Tumba, Sweden). Freestalls contained mats of hard rubber material and sawdust as bedding. Cows had free access to water and the VMS at all times throughout the study period. Cows were weighed automatically at each milking via an electronic scale placed in the VMS, and average daily BW was calculated.

\section{Experimental Design and Diets}

Before the start of the experimental period, all cows were fed the same standard TMR for ad libitum intake (i.e., control diet; Table 1), as is common practice on Danish dairy farms, and all cows were allowed $3 \mathrm{~kg} / \mathrm{d}$ of VMS concentrates (Table 2). Chemical composition in Table 1 reflects only the TMR without VMS concentrates; Table 2 lists the ingredient and chemical composition of VMS concentrates. The 19-d experiment consisted of 3 periods (i.e., before restriction, during restriction, and recovery). Before restriction, an 8 -d adjustment period was implemented for all cows in which feed intake, BW, daily milk production, and milk composition were measured starting $5 \mathrm{~d}$ before restriction (i.e., -120 to $0 \mathrm{~h}$ relative to restriction). The TMR was mixed once daily and fed at $0900 \mathrm{~h}$ using individual automatic feeding stations. The TMR averaged $100 \%$ of NRC (2001) requirements for $\mathrm{NE}_{\mathrm{L}}$ before restriction. Cows were fed to ensure a minimum of $10 \%$ daily refusals and daily feed intake was automatically registered (Chapinal et al., 2007).

During restriction (i.e., $0-96 \mathrm{~h}$ relative to nutrient restriction), dietary nutrient intake was restricted for 4 $\mathrm{d}$ for all cows by substituting $60 \%$ of the control TMR with wheat straw (restricted diet; Table 1). This type of feeding strategy was designed to allow for ad libitum 
Table 1. Ingredients and nutrient composition of experimental diets fed to Holstein dairy cows during lactation

\begin{tabular}{lcc}
\hline & \multicolumn{2}{c}{ Diet, ${ }^{1} \%$ of DM } \\
\cline { 2 - 3 } Item & Control & Restriction \\
\hline Ingredient & & \\
Grass silage, first harvest & 19.1 & 7.5 \\
Grass silage, fourth harvest & 15.5 & 6.1 \\
Spring barley & 16.8 & - \\
Corn silage & 34.5 & 13.5 \\
Barley straw & - & 60.0 \\
Rapeseed meal & 5.7 & 2.2 \\
Soybean meal, 44\% CP & 6.6 & 7.9 \\
Salt & 0.6 & 0.9 \\
Vitamin/mineral mix ${ }^{2}$ & 1.2 & 1.9 \\
Composition & 42.8 & 63.2 \\
DM, \% & 16.9 & 12.0 \\
CP & 19.5 & 3.9 \\
Starch & 7.0 & 3.2 \\
Sugar & 2.9 & 1.9 \\
Crude fat & 31.0 & 58.2 \\
NDF & 7.7 & 9.1 \\
Ash & 1.57 & 0.97 \\
NE, Mcal/kg of DM & & \\
\hline
\end{tabular}

${ }^{1}$ Control $=$ TMR balanced to provide $\sim 100 \%$ of NRC (2001) requirements for $\mathrm{NE}_{\mathrm{L}}$ and cows allowed $3 \mathrm{~kg}$ of concentrates/d in the automatic milking system (VMS; Voluntary Milking System, DeLaval, Tumba, Sweden); Restriction = dietary nutrients restricted for al cows by supplementing $60 \%$ of the control TMR with wheat straw and cows allowed a maximum intake of $1.0 \mathrm{~kg}$ of VMS concentrates/d. To avoid unwanted effects due to protein supply, the restriction diet was adjusted to maintain a dietary protein content of $12 \%$.

${ }^{2}$ Vitamin and mineral mix (Komix 95312; Vitfoss, Gråsten, Denmark) contained a minimum of $3,842 \mathrm{mg} / \mathrm{kg}$ of $\mathrm{Mn}, 6,667 \mathrm{mg} / \mathrm{kg}$ of Zn, 1,385 $\mathrm{mg} / \mathrm{kg}$ of Cu, $200 \mathrm{mg} / \mathrm{kg}$ of I, $31.2 \mathrm{mg} / \mathrm{kg}$ of Co, $27.9 \mathrm{mg} / \mathrm{kg}$ of Se, $566,000 \mathrm{IU} / \mathrm{kg}$ of vitamin $\mathrm{A}, 101,600 \mathrm{IU} / \mathrm{kg}$ of vitamin $\mathrm{D}_{3}$, and 1,029 $\mathrm{IU} / \mathrm{kg}$ of vitamin $\mathrm{E}$.

intake and maintain gut fill while limiting nutrient intake. To avoid unwanted effects due to protein supply, the mix was adjusted to maintain a dietary protein content of $12 \%$. To prevent separation of the straw and control TMR, $300 \mathrm{~mL}$ of water $/ \mathrm{kg}$ of feed was added during mixing. During the restriction period, cows were offered and consumed a total of $1.0 \mathrm{~kg}$ of concentrate in the VMS per day. After 4-d of nutrient restriction, cows returned to the control diet and were monitored for an additional $7 \mathrm{~d}$ (i.e., recovery period; 97-264 h relative to nutrient restriction).

\section{Feed Sampling and Analysis}

Samples of all individual TMR ingredients (Table 1) and VMS concentrates (Table 2) were taken weekly and pooled monthly during the study and analyzed for DM content (weekly), CP, crude fat, ash, sugar, starch and NDF using standard methods at Aarhus University, formerly known as the Danish Institute of Agricultural Sciences (Anonymous, 1992). Net energy for lactation was calculated based on values for individual ingredi- ents and VMS concentrations provided by the Nordic Feed Evaluation System (NorFor; http://feedstuffs.norfor.info). The composition of feed refusals was assumed similar to the diet offered.

\section{Milk Sampling and Analysis}

At each milking, milk yield was recorded and composite milk samples were collected automatically via VMS. Daily milk yield was calculated and composite milk samples collected at each milking were analyzed for fat (\%), protein (\%), lactose (\%), citrate (\%), and SCC (cells/mL) using a CombiFoss 4000 (Foss Electric A/S, Hillerød, Denmark). A subset of composite milk samples was collected between 1630 and $0600 \mathrm{~h}$ and analyzed for BHBA, MUN, uric acid (UA), and alkaline phosphatase activity (AP). Milk BHBA $(\mathrm{m} M)$ was analyzed using the enzymatic oxidation of the metabolite. A coupled reaction was determined by fluorometry (Larsen and Nielsen, 2005). Milk AP activity (IU/L) was analyzed as described by Larsen et al. (2010), where activities were determined by kinetic, fluorometric detection, using 4-methylumbelliferone phosphate (4-MeU-P) as the substrate (41504-0010, Acros Organics, Geel, Belgium). Milk UA was analyzed following procedures described by Larsen and Moyes (2010). Milk urea nitrogen was analyzed using flow injection analyses following the manufacturer's instructions (Foss Tecator AB, Höganäs, Sweden). Briefly, urease (EC 3.5.1.5) was added to the diluted milk sample. After the reaction, a strong alkali solution was added and the developing ammonia was dialyzed through a membrane. $\mathrm{pH}$ changes

Table 2. Ingredient and chemical composition of automatic milking system concentrates ${ }^{1}$

\begin{tabular}{lc}
\hline Item & \% of DM \\
\hline Ingredient & \\
Sunflower meal & 15.0 \\
Distillers corn grain & 15.0 \\
Dried sugar-beet pulp & 15.0 \\
Wheat & 12.4 \\
Rapeseed meal & 10.4 \\
Soybean hulls & 0.91 \\
Wheat bran & 0.9 \\
Dried grass & 0.8 \\
Molasses, cane & 0.3 \\
Vegetable fat & 0.13 \\
Mineral and vitamin mix & 0.18 \\
Composition & \\
DM, \% & 87.9 \\
CP & 22.4 \\
Starch & 10.4 \\
Sugar & 3.7 \\
Crude fat & 5.0 \\
NDF & 31.8 \\
Ash & 7.8 \\
NE & Mcal/kg of DM \\
\hline
\end{tabular}


in the passing, aqueous phase were followed by a $\mathrm{pH}$ indicator using a spectrophotometer, and high and low control samples were analyzed continuously during the analysis. Accuracy was $-1.2 \%$ and $+0.4 \%$ (bias) for low and high controls, respectively. Correspondingly, intraassay variation was 1.9 and $1.1 \%(\mathrm{CV})$. Cows that had not voluntarily entered the VMS between 1630 and $0600 \mathrm{~h}$ were escorted to the VMS by herd personnel for milking before the end of this period to ensure a milk sample was collected and analyzed for components mentioned above.

\section{Calculation of Energy Balance}

Daily DMI and calculated $\mathrm{NE}_{\mathrm{L}}$ density of the TMR were used to determine $\mathrm{NE}_{\mathrm{L}}$ intake for each cow (including VMS concentrate). Average daily BW before restriction was used to calculate energy requirements for maintenance because changes in BW during the 4-d restriction period were due to gut fill. Energy requirements for maintenance were calculated according to NRC (2001) equations, where requirement $=\left[\mathrm{BW}_{\text {before }}\right.$ restriction $\left.(\mathrm{kg})^{0.75}\right] \times[0.08 \mathrm{Mcal} / \mathrm{kg}]$. Energy requirements for milk production (NRC, 2001) were calculated as $\mathrm{NE}_{\mathrm{L}}(\mathrm{Mcal} / \mathrm{kg})=$ milk yield $\times[(0.0929 \times \%$ fat $)+$ $(0.0547 \times \%$ protein $)+(0.0395 \times \%$ lactose $)]$, and energy balance (Mcal/d) was calculated as $\left[\mathrm{NE}_{\mathrm{L}}\right.$ intake - (maintenance energy + milk energy output)].

\section{Blood Collection and Analysis}

Blood samples were collected in the mornings $(\sim 0900$ h) at $-72,-24,24,48,72,96,120,144,216$, and 264 $\mathrm{h}$ relative to the start of dietary nutrient restriction by puncture of the coccygeal vein/artery using Vacutainer tubes containing sodium heparin (BD Vacutainer Systems, Plymouth, UK). Plasma was harvested following centrifugation at $2,000 \times g$ for $20 \mathrm{~min}$ at $4^{\circ} \mathrm{C}$ and stored at $-18^{\circ} \mathrm{C}$ until further analysis. All plasma components were analyzed using an autoanalyzer (ADVIA 1650 Chemistry System, Siemens Medical Solution, Tarrytown, NY) according to methods described below. Plasma glucose, TAG, total protein, cholesterol, aspartate transferase (AST), PUN, albumin, alkaline phosphatase (ALP), and $\gamma$-glutamyl transferase (GGT) were determined according to standard procedures (Siemens Diagnostics Clinical Methods for ADVIA 1650). Plasma NEFA was determined using the NEFA C ACS-ACOD assay method and phospholipids were analyzed according to the Choline Oxidase, DAOS assay method (Wako Chemicals GmbH, Neuss, Germany). Total bile acids (TBA) were analyzed using an enzymatic colorimetric assay (Randox Laboratories Ltd., Co. Antrim, UK). Ceruloplasmin (Olishevsky et al., 2006) was determined kinetically as oxidase activity. Haptoglobin was determined chemically due to its ability to bind to hemoglobin (Phase, Tridelta Developments, Wicklow, Ireland). Plasma BHBA was determined as an increase in absorbance at $340 \mathrm{~nm}$ due to the production of $\mathrm{NADH}$ at slightly alkaline $\mathrm{pH}$ in the presence of BHBA dehydrogenase; a sample blank was included. The method involved oxamic acid in the media to inhibit lactate dehydrogenase as proposed by Harano et al. (1985). Plasma insulin was analyzed via time-resolved fluoro-immunometric assay (Perkin Elmer, Skovlunde, Denmark) using a bovine insulin standard as described by Løvendahl and Purup (2002).

\section{Sampling and Analysis of Liver}

For a subset of cows in early $(\mathrm{n}=13)$ and mid lactation $(\mathrm{n}=11)$ only, liver biopsies were taken in the mornings $(\sim 0900 \mathrm{~h})$ at $-24,72$, and $144 \mathrm{~h}$ relative to the start of nutrient restriction. Ten cows were primiparous and 14 cows were multiparous. Liver biopsies (12 $\times 20$-mg biopsies) were collected via an incision on the right side of the cows at the 10th intercostal, where it crossed a line from mid humerus to tuber coxae. Prior to collection, a $5 \times 5 \mathrm{~cm}$ area was shaved and disinfected and $5.0 \mathrm{~mL}$ of local anesthesia (Procasel 2\%; Selectavet, Weyarn-Holzolling, Germany) was given. After a minimum of $10 \mathrm{~min}$, a 0.5 -cm incision was made in the skin. Liver biopsies were taken from the incision using a Manan Automatic Biopsy System (14 gauge $\times$ 17-mm notch; Marmon/MDTech, Gainesville, FL). The incision area was closed using a single-use skin stapler (AutoSuture Royal 35W Stapler, United States Surgical Corporation, Norwalk, CT). Tissue was frozen immediately in liquid $\mathrm{N}$, and transferred to a $-80^{\circ} \mathrm{C}$ freezer for storage until analysis.

Two tubes of liver tissue ( $\sim 25 \mathrm{mg}$ of wet weight) were transferred to 2 separate 2-mL Eppendorf tubes at $-20^{\circ} \mathrm{C}$. For lipid extraction (i.e., tube 1), $0.33 \mathrm{~mL}$ of chloroform with $0.67 \mathrm{~mL}$ of methanol (2:1) was added, whereas $0.8 \mathrm{~mL}$ of PBS (pH 7.4) was added to tube 2 for glycogen and glucose extraction. Tissues were homogenized (Retsch TissueLyzer; Qiagen Retsch, Haan, Germany) and $0.2 \mathrm{~mL}$ of $5 \%$ Triton X-100 solution was then added to tube 2 . All tubes were then centrifuged at $2,000 \times g$ at $20^{\circ} \mathrm{C}$ for $15 \mathrm{~min}$ and the resulting supernatants were transferred to a separate 5 -mL Sarstedt tube.

Liver lipids were extracted according to procedures described by Folch et al. (1957), with modifications. For tube $1,1.0 \mathrm{~mL}$ of chloroform and $0.5 \mathrm{~mL}$ of a solution of $0.04 \% \mathrm{CaCl}_{2}, 0.034 \% \mathrm{MgCl}_{2}$ and $0.58 \% \mathrm{NaCl}$ were added to the supernatant and centrifuged at 2,000 $\times g$ at $20^{\circ} \mathrm{C}$ for $15 \mathrm{~min}$ to promote biphasic separation in 
upper and lower phases. The upper phase was decanted and $0.25 \mathrm{~mL}$ of methanol was added and then dried at $50^{\circ} \mathrm{C}$ under constant $\mathrm{N}_{2}$ airflow for 30 min (ZipVap Evaporator, Glas-Col, Terre Haute, IN). The dried extract was redissolved and saponified in $1.2 \mathrm{~mL}$ of 0.5 $M \mathrm{KOH}$-ethanol in a $60^{\circ} \mathrm{C}$ water bath for $30 \mathrm{~min}$. The hydrolyzed extract was mixed thoroughly, whereupon $0.6 \mathrm{~mL}$ was transferred to a new 5 -mL Sarstedt tube and neutralized with $1.4 \mathrm{~mL} 0.15 \mathrm{M} \mathrm{MgSO}_{4}$.

Liver glycogen was analyzed following procedures described by Andersen et al. (2002). Choline containing phospholipid was determined by the Choline Oxidase, DAOS Method (Wako Pure Chemical Industries). Glucose and TAG content were determined as described above for plasma.

\section{Statistical Analysis}

Because a robotic milking system was used for this study, daily milk yield for each cow was calculated based on hourly milk yield, where $Y_{\mathrm{h}}=\mathrm{Yield}_{\mathrm{C}} /\left(\mathrm{T}_{\mathrm{C}}-\right.$ $T_{P}$ ), where $Y_{h}=$ hourly yield per cow per visit; Yield $_{C}$ $=$ total yield $(\mathrm{kg})$ of milk measured at the current visit; $\mathrm{T}_{\mathrm{C}}=$ time of day (i.e., h:min:sec) at the start of the current visit; and $\mathrm{T}_{\mathrm{P}}=$ time of day at the end of the previous visit. Because feed changes occurred at $0900 \mathrm{~h}$ during the restriction and recovery periods, a 24-h day was defined as 0900 to $0900 \mathrm{~h}$; from this, daily milk yield was calculated. The average frequency of visits/ cow per day was 2.2 with $95 \%$ of cows producing $>7.6$ $\mathrm{kg}$ of milk per visit. For milk composition only, cows with $<5 \mathrm{~kg}$ of milk at any given visit were not used for statistical analysis.

For each cow at each time point, the ratio between plasma glucose $(\mathrm{m} M)$ and insulin $(\mathrm{ng} / \mathrm{mL} ; \mathbf{G}: \mathbf{I})$ and the revised quantitative insulin sensitivity check index (RQUICKI) were calculated. The RQUICKI was calculated (Holtenius and Holtenius, 2007) in the following manner: RQUICKI $=1 /[\log$ (glucose $)+\log ($ insulin $)$ $+\log (\mathrm{NEFA})]$. The $\log _{10}$ of milk SCC was used and all blood and liver parameters, except plasma glucose, albumin, phospholipids, cholesterol, and PUN, were natural $\log (\ln )$ transformed for statistical analysis. Prior to analysis, pre-restriction averages were calculated for each parameter. To identify the magnitude of the effects of nutrient restriction relative to stage of lactation on metabolites and production parameters, the percentage change $(\% \mathbf{c h g})$ relative to pre-restriction averages (i.e., 0\%) was calculated for each cow at each time point for all variables throughout the study period. The absolute values and the \%chg for each variable were analyzed via a generalized linear mixed model using the MIXED procedure of SAS version 9.2 (SAS Institute, 2008) with the repeated measure of time (i.e., hour) relative to start of dietary nutrient restriction (time $=0$ ). The random effect of cow was used as the error term in the REPEATED statement with auto-regressive $1[\mathrm{AR}(1)]$ and unstructured as the covariance structure for the \%chg and absolute values, respectively. The model was used to determine the effect of stage of lactation on production and metabolic responses of cows during dietary nutrient restriction. Preliminary analyses showed that parity, as well as the interaction of parity and stage of lactation, had a minimal effect on production and metabolic responses; therefore, the effect of parity only (i.e., no interactions) was included in the final model. For absolute values, the class variables included cow, parity, stage of lactation, and time relative to restriction with the model $Y_{i j k l}=\mu+P_{j}+S_{k}+H_{l}+S_{k} \times H_{l}+C_{i}+e_{i j k l}$, where $Y_{i j k l}=$ dependent variable at time $l(l=0,24,48,72$, $96,120,144,168,192,216,240$, and 264) for the $i$ th cow at the $j$ th parity ( $j=$ primiparous or multiparous) in the $k$ th stage of lactation ( $k=$ early, mid, or late); $\mu=$ overall mean; $P_{j}=$ effect of parity; $S_{k}=$ the effect of stage of lactation; $H_{l}=$ the effect of time relative to nutrient restriction; $C_{i}=$ the random effect of cow $i$; and $e_{i j k l}=$ the experimental error. For \%chg, parity was excluded from the model because the effect was not significant $(P>0.05)$, and the class variables included cow, stage of lactation, and time relative to restriction with model $Y_{i k l}=\mu+H_{l}+S_{k} \times H_{l}+C_{i}+e_{i k l}$, where $Y_{i k l}=$ dependent variable at time $l$ for the $i$ th cow at the $k$ th stage of lactation; $\mu=$ overall mean; $H_{l}=$ the effect of time $l(l=24,48,72,96,120,144,168,192$, 216,240 , and 264) relative to nutrient restriction; $C_{i}=$ the random effect of cow $i$; and $e_{i k l}=$ the experimental error. Stage effects on \%chg variables are expressed in the stage $\times$ time interaction term. For both models, the degrees of freedom were estimated with the KenwardRoger specification in the model statements. Data are presented as LSM and SEM. Separation of LSM for significant effects was accomplished using the Tukey's option within the MIXED procedure of SAS. Statistical differences were declared as significant and highly significant at $P<0.05$ and $P<0.01$, respectively. Trends toward significance are discussed at $P<0.10$.

PROC CORR was used to generate correlations among absolute values over time. To further explore and quantify the influence of cow level variability on the observed responses, and how this interacted with stage of lactation and parity effects, regression analyses (PROC GLM) were used to predict whether pre-restriction levels of individual parameters (i.e., Level $_{\text {Before }}$ ) explain changes in levels during restriction (i.e., LevelDuring) and whether this is altered by stage of lactation. Before regression analysis, averages for each parameter (e.g., daily milk yield, DMI, milk protein content, milk 
BHBA, and plasma BHBA, NEFA, and glucose) were calculated for each cow within each period (i.e., before restriction, during restriction, and recovery). The linear model included $Y_{i j k}=$ Level $_{\text {Before }}+S_{k}+P_{j}+$ Level $_{\text {Before }}$ $\times S_{k}+$ Level $_{\text {Before }} \times P_{j}+e_{i j k}$, where $Y_{i j k}=$ average during nutrient restriction for the $i$ th cow within the $j$ th parity at the $k$ th stage of lactation, Level $_{\text {Before }}=$ average level before restriction, and other variables are defined above. The Type III sums of squares were used to determine whether these effects were significant $(P$ $<0.10)$.

In a further step in this exploratory analysis of causal factors, PROC GLM was used to examine whether DIM or milk yield before restriction is a better predictor of changes in production and metabolic responses during restriction. Prior to analysis, the systematic effect of parity was adjusted for using PROC MIXED, with hour as the repeated measure using autoregressive 1 . Averages of the residuals generated from the MIXED procedure were then calculated for each cow within each period. The averaged residuals were then used for the PROC GLM regression analysis with model $Y_{i}$ $=D E P E N D+e_{i}$, where $Y_{i}=$ average residual during nutrient restriction for the $i$ th cow, DEPEND = either average residual daily milk yield or DIM before nutrient restriction, and $e_{i}=$ unexplained variation.

\section{RESULTS}

Figure 1 shows the profiles of daily DMI (Figure 1A), calculated energy balance (Figure 1B), and daily milk yield (Figure 1C) at time points relative to nutrient restriction for cows at different stages of lactation. Prior to restriction, cows in early lactation had higher (stage $\times$ time: $P<0.001)$ milk yield $(42.1 \pm 1.7 \mathrm{~kg} / \mathrm{d})$ than cows in mid $(30.8 \pm 1.6 \mathrm{~kg} / \mathrm{d})$ or late $(26.8 \pm 1.5$ $\mathrm{kg} / \mathrm{d}$ ) lactation, and cows in early lactation were in lower calculated energy balance $(-4.4 \pm 1.2 \mathrm{Mcal} / \mathrm{d})$ than cows in mid $(2.5 \pm 1.1 \mathrm{Mcal} / \mathrm{d})$ or late $(2.4 \pm 1.0$ $\mathrm{Mcal} / \mathrm{d}$ ) lactation. During restriction, the \%chg in milk yield (data not shown) was similar among groups and did not differ at any given time point during restriction. After $48 \mathrm{~h}$ of restriction, cows in early lactation were in lower calculated energy balance than cows in late lactation. Dry matter intake $(21.1 \pm 3.3 \mathrm{~kg} / \mathrm{d})$ was not different (stage $\times$ time: $P=0.26$ ) among cows at different stages of lactation before nutrient restriction. During restriction, decreases in DMI were similar for all cows, regardless of stage of lactation. During the recovery period, all cows returned to pre-restriction levels for all parameters, regardless of stage of lactation.

Figure 2 shows the differences in plasma concentrations of glucose (Figure 2A), \%chg in glucose (Figure 2B), insulin (Figure 2C), and the G:I ratio (Figure 2D) at time points relative to nutrient restriction for cows at different stages of lactation. Prior to restriction, cows in early lactation had lower $(P<0.05)$ plasma glucose concentration than cows in mid lactation, whereas insulin did not differ $(P>0.10)$ among groups. Nutrient restriction resulted in lower glucose (time: $P<0.001$ ), regardless of stage of lactation, and a greater \%chg in plasma glucose (stage $\times$ time: $P<0.001$ ) was observed for cows in early $(-18.2 \pm 1.8 \%)$ than cows in mid $(-8.37 \pm 1.7 \%)$ and late $(-7.76 \pm 1.6 \%)$ lactation. During the recovery period, we observed a marked increase in plasma glucose concentration at $120 \mathrm{~h}$ relative to restriction for cows in early lactation, which was greater than that of cows in late lactation only. However, by $264 \mathrm{~h}$, glucose concentrations remained lower during the recovery period for cows in mid and late lactation, whereas it returned to pre-restriction levels for cows in early lactation. Plasma insulin concentration decreased (time: $P<0.001$ ) during restriction for all cows but, unlike glucose, insulin concentration was not altered by stage of lactation (stage $\times$ time: $P=$ 0.15). In addition, insulin concentration returned to pre-restriction levels during the recovery period for all cows, regardless of stage of lactation. Cows in early lactation had greater (stage $\times$ time: $P<0.05$ ) G:I ratio than cows in late lactation at 24 and $72 \mathrm{~h}$ relative to restriction (Figure 2D). No differences in RQUICKI value were observed among groups at any given time point throughout the study period (Figure 3A); however, the \%chg in RQUICKI (stage $\times$ time: $P<0.001$; Figure 3B) was higher for cows in early lactation than for cows in late lactation during restriction.

Figure 4 shows the differences in plasma concentrations of NEFA (Figure 4A), and \%chg in NEFA (Figure $4 \mathrm{~B}$ ) and BHBA (Figure 4C) at time points relative to nutrient restriction for cows at different stages of lactation. Before restriction, NEFA were higher $(P<$ $0.01)$ for cows in early than cows in mid and late lactation, whereas BHBA concentration was similar among groups. During restriction, a greater \%chg in NEFA (stage $\times$ time: $P<0.001)$ was observed for cows in mid $(37.8 \pm 2.8 \%)$ and late $(39.7 \pm 2.6 \%)$ than cows in early $(23.1 \pm 2.9 \%)$ lactation. During restriction, plasma BHBA concentration (stage $\times$ time: $P<0.001$ ) increased for cows in early lactation, whereas no changes were observed for cows in mid and late lactation. During the recovery period, NEFA and BHBA concentration returned to pre-restriction levels for all cows.

No differences $(P>0.10)$ were observed among groups before restriction for plasma concentration of cholesterol (Figure 5A) and PUN (Figure 5C). Cholesterol increased for all cows during restriction but no differences were observed among groups. During the recovery period, cholesterol returned to pre-restriction 


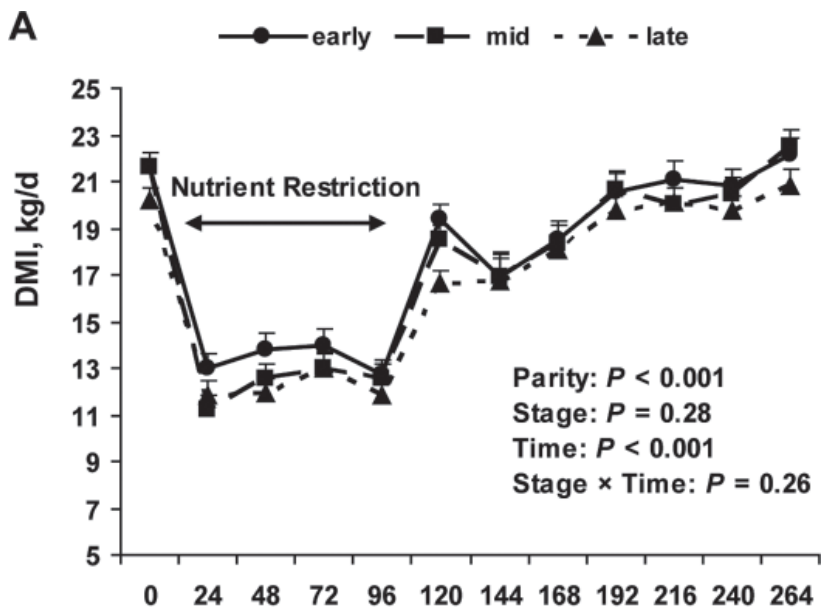

B

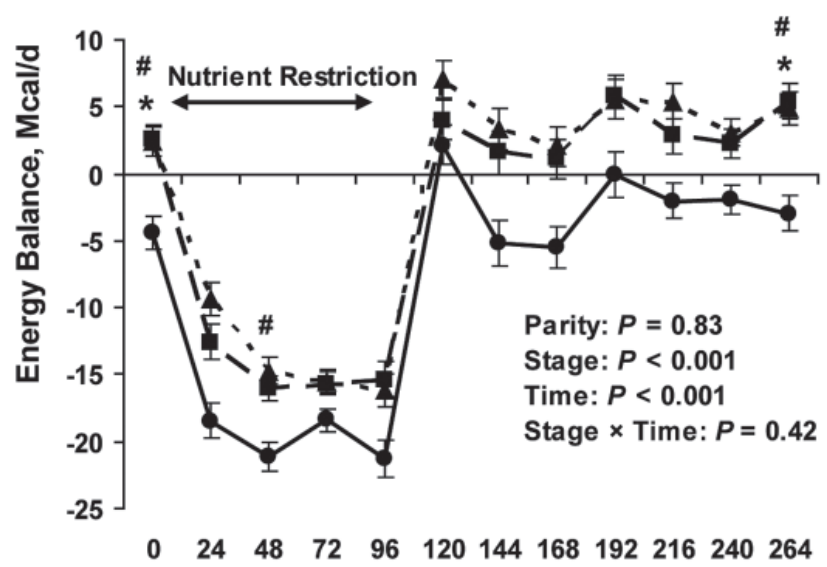

C

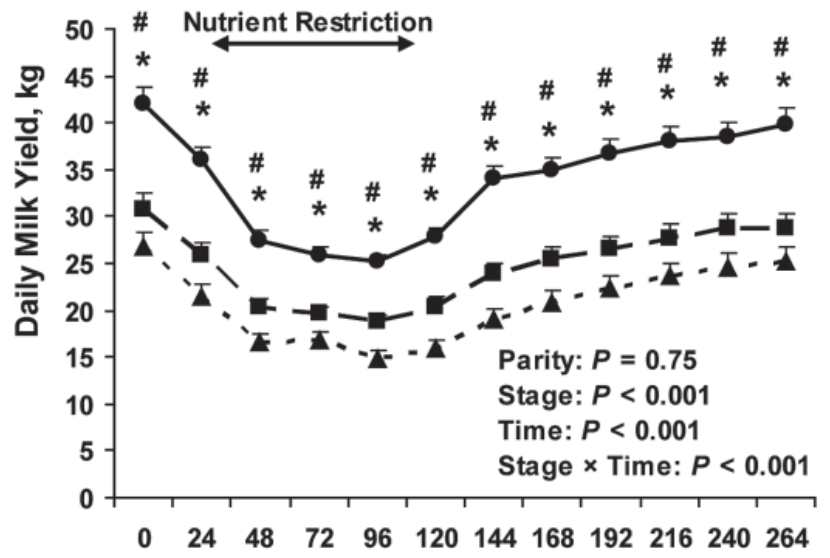

Time Relative to Nutrient Restriction (0-96 h)

Figure 1. Profiles of daily DMI (A), calculated energy balance (B), and daily milk yield $(\mathrm{C})$ at time points (i.e., hour) relative to dietary nutrient restriction ( $\mathrm{h}=0-96)$ for 47 Holstein cows in early $(\bullet)$, mid $(\boldsymbol{\square})$, and late $(\boldsymbol{\Lambda})$ lactation. Time $=0$ reflects the average during an 8 -d adjustment period within stage of lactation. ${ }^{*}$ Differences $(P<$ $0.05)$ between cows in early and mid lactation at any given time point; \#Differences $(P<0.05)$ between cows in early and late lactation at any given time point. values for cows in mid and late lactation. For cows in early lactation, a tendency for increased concentration of cholesterol was observed for cows in early lactation compared with pre-restriction levels and is reflected in a greater \%chg in cholesterol (Figure 5B) for cows in early lactation compared with those in late lactation during the recovery period. Plasma urea nitrogen decreased (time: $P<0.001$ ) for all cows during restriction, regardless of lactation (Figure $5 \mathrm{C}$ ). At $72 \mathrm{~h}$ relative to restriction, the \%chg in PUN (Figure 5D) for cows in early lactation was less pronounced than for cows in mid and late lactation. Stage of lactation did not alter responses in plasma TAG, total protein, AST, ALP, GGT, TBA, phospholipid, albumin, haptoglobin, and ceruloplasmin during dietary nutrient restriction to increase PI (data not shown).

Prior to restriction, no differences were observed between cows in early and mid lactation with regards to concentration of liver glycogen (Figure 6B), whereas liver TAG content (Figure 6A) was greater for cows in early $(0.10 \pm 0.01 \mathrm{mM})$ than for those in mid lactation $(0.05 \pm 0.01 \mathrm{mM})$ and tended $(P=0.08)$ to be greater during the recovery period. Liver tissue was not collected from cows in late lactation and results are shown for differences between cows in early and mid lactation only. For all cows, nutrient restriction increased liver TAG (time: $P<0.001$ ) and decreased glycogen (time: $P<0.001$ ); and liver glycogen content was lower during restriction for cows in early than cows in mid lactation. During the recovery period, liver TAG remained elevated when compared with pre-restriction levels whereas liver glycogen concentration returned to pre-restriction levels for both groups. Stage of lactation did not alter responses in liver glucose, phospholipid and total liver lipid during the dietary restriction period (data not shown).

Figure 7 shows the differences in concentrations of milk BHBA (Figure 7A), protein (Figure 7B), lactose (Figure 7C), UA (Figure 7D), MUN (Figure 7E) and citrate (Figure $7 \mathrm{~F}$ ) at time points relative to nutrient restriction for cows at different stages of lactation. Prior to restriction, milk BHBA, UA, lactose, MUN, and citrate were similar among groups, whereas milk protein tended $(P=0.07)$ to be for lower for cows in early versus late lactation. During restriction, milk BHBA increased (stage $\times$ time: $P<0.01$ ) for cows in early lactation, whereas no changes in milk BHBA were observed for cows in mid and late lactation. Regardless of stage of lactation, milk lactose decreased (time: $P<$ 0.001 ) during restriction. Milk protein decreased (stage $\times$ time: $P<0.001$ ) for cows in early and mid lactation during restriction, whereas no changes were observed for cows in late lactation. During the recovery period, milk BHBA, fat, protein, lactose, MUN, and citrate 


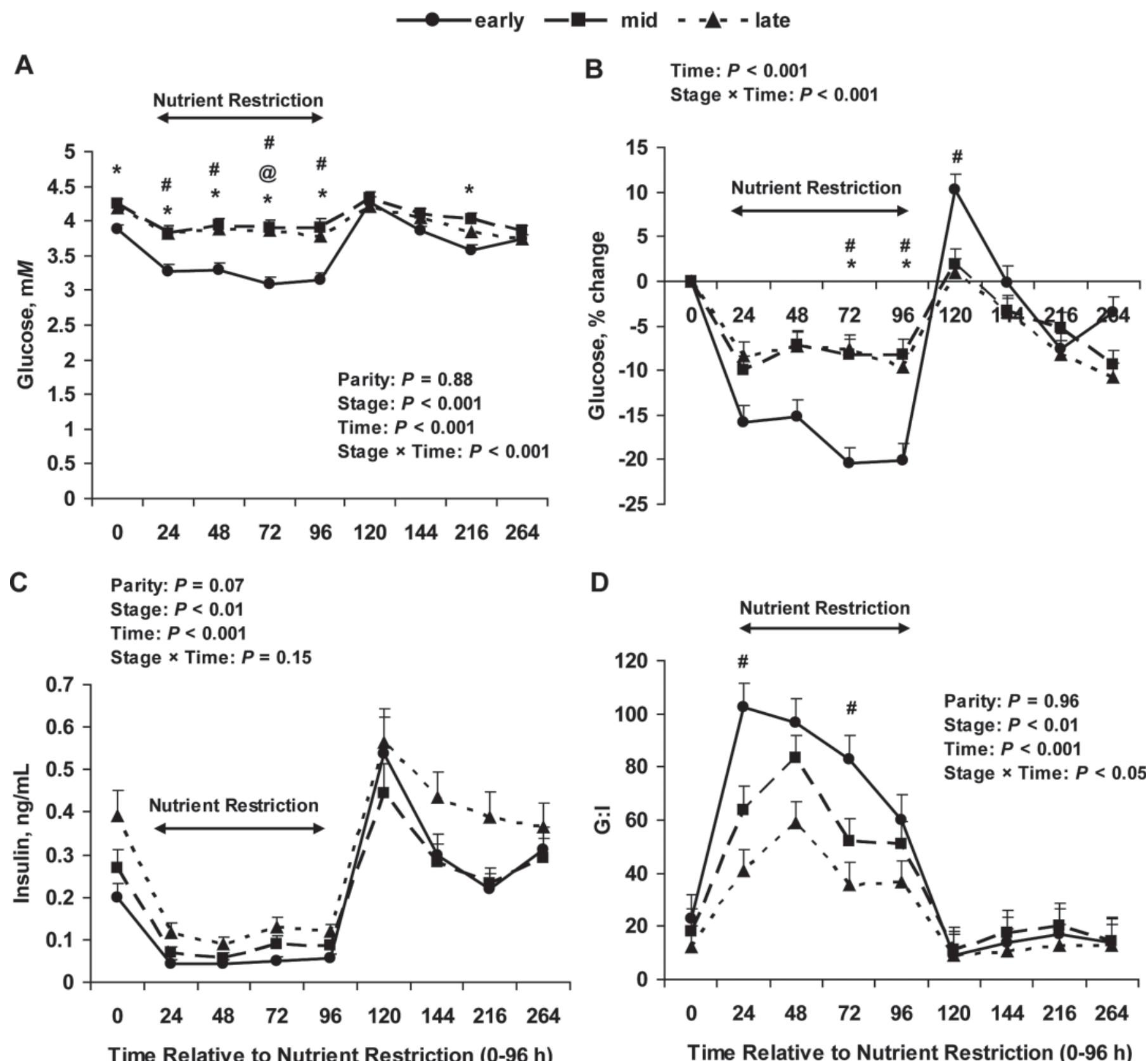

Figure 2. Differences in plasma concentrations of glucose (A), percentage change in glucose (B), insulin (C), and glucose:insulin (G:I) ratio (D) at time points (i.e., hour) relative to dietary nutrient restriction $(\mathrm{h}=0-96)$ in 47 Holstein cows in early $(\mathbf{\bullet})$, mid $(\boldsymbol{\square})$, and late $(\mathbf{\Delta})$ lactation. Time $=0$ reflects the average during an 8-d adjustment period within stage of lactation. ${ }^{*}$ Differences $(P<0.05)$ between cows in early and mid lactation at any given time point. \#Differences $(P<0.05)$ between cows in early and late lactation at any given time point. @Differences $(P<0.05)$ between cows in mid and late lactation at any given time point. G:I $=$ the ratio between plasma glucose $(\mathrm{m} M)$ and insulin $(\eta \mathrm{g} / \mathrm{mL})$.

concentrations returned to pre-restriction levels for all cows, regardless of stage of lactation. Interestingly, milk UA remained unchanged during restriction but increased (time: $P<0.001$ ) during the early stages of the recovery period for all cows, regardless of stage of lactation. Stage of lactation did not alter responses in milk SCC, fat and AP content during restriction (data not shown).

Figure 8 shows the \%chg for daily milk yield, milk BHBA, UA, fat, citrate, and MUN for cows in early (Figure 8A) and mid and late lactation (Figure 8B) throughout the study period. Average \%chg for cows in 


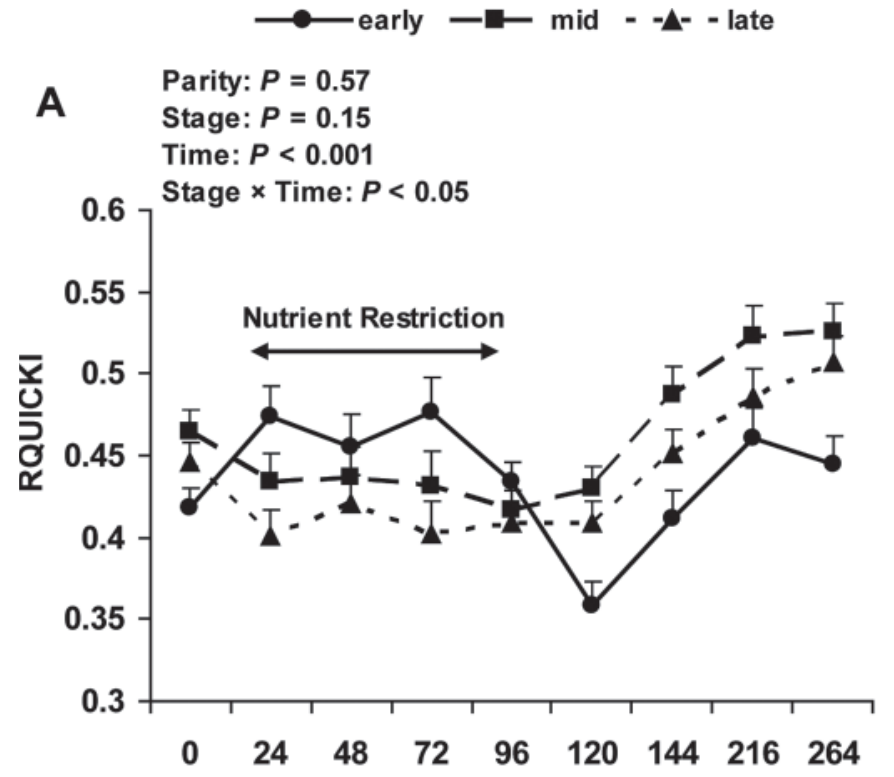

B Time: $P<0.001$

Stage $\times$ Time: $P<0.001$

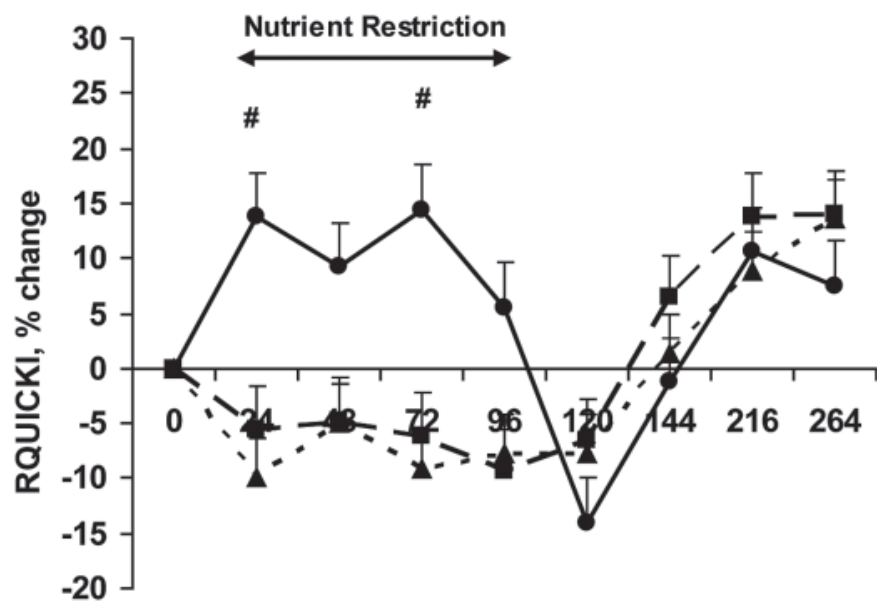

Time Relative to Nutrient Restriction (0-96 h)

Figure 3. Differences in the revised quantitative insulin sensitivity check index (RQUICKI) value (A) and the percentage change in the RQUICKI value (B) at time points (i.e., hour) relative to dietary nutrient restriction $(\mathrm{h}=0-96)$ in 47 Holstein cows in early $(\bullet)$, mid $(\boldsymbol{\square})$, and late $(\mathbf{\Lambda})$ lactation. Time $=0$ reflects the average during an 8-d adjustment period within stage of lactation. \#Differences $(P$ $<0.05$ ) between cows in early and late lactation at any given time point. RQUICKI calculated as RQUICKI $=1 /[\log ($ plasma glucose $)+$ $\log ($ plasma insulin $)+\log ($ plasma NEFA $)]$ described by Holtenius and Holtenius (2007).

mid and late lactation was calculated because similar responses were observed between groups for each variable shown. Separation of early and mid/late lactation identifies potential biomarkers in milk for PI that are similar and differ by stage of lactation. After $48 \mathrm{~h}$ of restriction, \%chg in milk citrate concentration was the greatest $(\sim 58 \%)$ for all cows compared with fat $(\sim 42 \%)$, and milk yield $(\sim-35 \%)$. For cows in early lactation, peak changes in BHBA in milk $(77 \%)$ were not observed until $96 \mathrm{~h}$ of restriction.

Table 3 shows the linear regression model for the relationship between DIM and milk yield before nutrient restriction and DMI, EBAL, milk protein and BHBA, plasma glucose, NEFA and BHBA, or liver glycogen and phospholipid content during restriction. After adjustments for the effect of parity, milk yield before restriction was a better indicator $(P<0.01)$ of DMI during restriction than DIM $(P=0.32)$. Milk protein and BHBA concentration (i.e., early lactation only) during restriction were associated $(P<0.01)$ with both milk yield and DIM before restriction, but DIM tended to be a stronger predictor (higher $\mathrm{R}^{2}$ and lower error mean square) than milk yield. In addition, DIM was a better indicator than milk yield with regard to changes in concentration of plasma NEFA and BHBA and liver glycogen content during restriction.

Parameter estimates and regression analysis information for the model selected to predict changes in plasma levels of NEFA, BHBA and glucose during restriction is shown in Table 4 . For all variables, parity and the interaction of parity $\times$ Level $_{\text {Before }}$ was not associated with changes in glucose, NEFA, and BHBA during restriction. For changes in plasma glucose, the final model included the effect of stage of lactation, Glucose Before $_{\text {, }}$ and the interaction of Glucose $_{\text {Before }} \times$ stage of lactation $\left(\mathrm{R}^{2}=0.68 ; P<0.001\right)$. Predictions for Glucose $_{\text {During }}$ were similar for cows in mid and late lactation, whereas Glucose $_{\text {Before }}$ tended $(P=0.08)$ to be a stronger predictor of Glucose $_{\text {During }}$ for cows in early lactation. Changes in NEFA during restriction were not associated with stage of lactation and $N E F A_{B e f o r e}$ was the best predictor of $N E F A_{\text {During }}\left(\mathrm{R}^{2}=0.38 ; P<0.001\right)$. Level of $B H B A_{B e-}$ fore, stage of lactation, and the interaction of $B H B A_{\text {Before }}$ $\times$ stage of lactation were used in the final model as predictors of $B H B A_{\text {During }}\left(\mathrm{R}^{2}=0.81 ; P<0.001\right)$. The greater slope for cows in early lactation indicates that $B H B A_{\text {Before }}$ explains more variance in $B H B A_{\text {During }}$ for cows in early compared with cows in mid and late lactation.

Parameter estimates and regression analysis information for the regression model selected to predict average daily milk yield, DMI, milk BHBA, and protein content during restriction are shown in Table 5 . For all variables, parity and the interaction of parity $\times$ Level $_{\text {Before }}$ were not associated with milk yield, DMI, milk BHBA, or protein during nutrient restriction. Milk yield and DMI during restriction were not associated with stage of lactation. Average daily milk yield and DMI before 

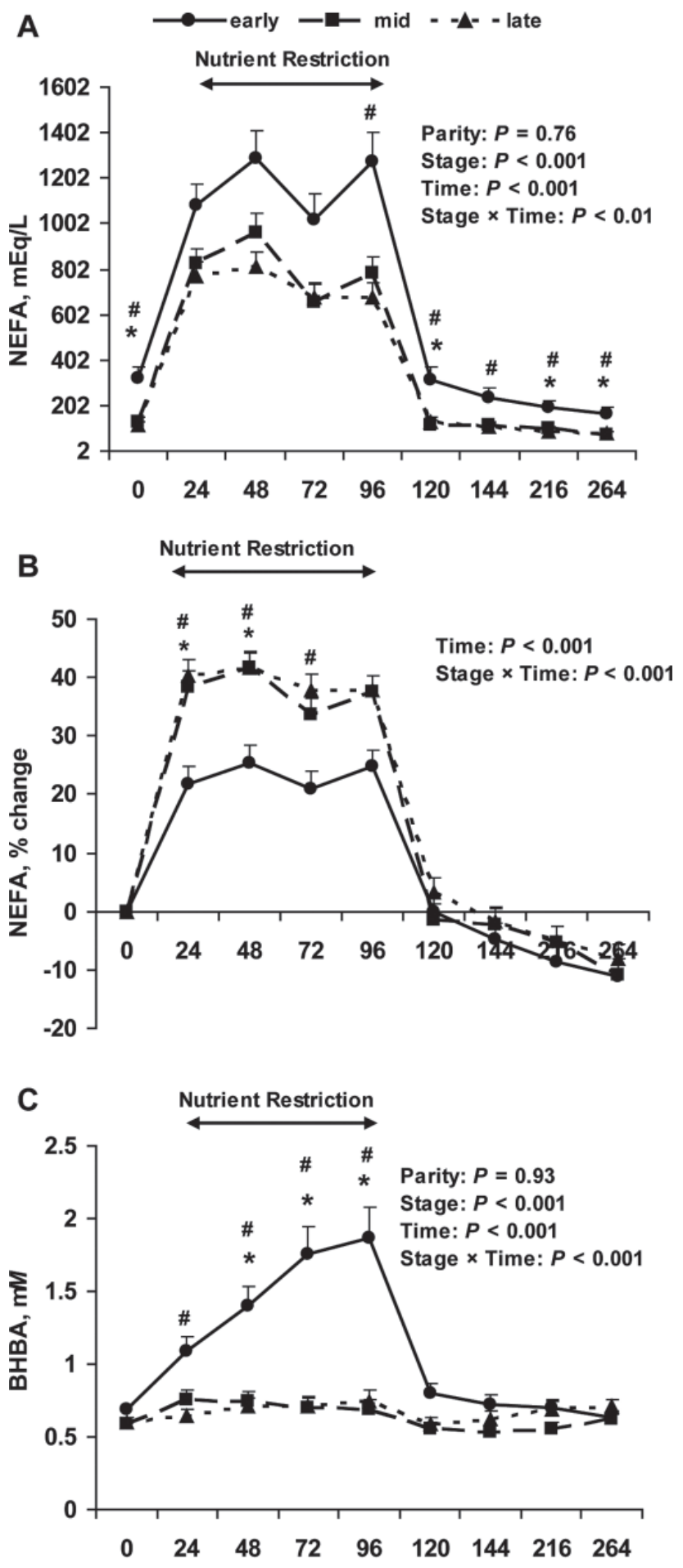

Time Relative to Nutrient Restriction (0-96 h)

Figure 4. Differences in plasma concentrations of NEFA (A), percentage change in NEFA (B), and BHBA (C) at time points (i.e., hour) relative to dietary nutrient restriction $(\mathrm{h}=0-96)$ in 47 Holstein cows in early $(\bullet)$, mid $(\boldsymbol{\square})$, and late $(\boldsymbol{\Delta})$ lactation. Time $=0$ reflects the average during an 8-d adjustment period within stage of lactation. *Differences $(P<0.05)$ between cows in early and mid lactation at any given time point; \#Differences $(P<0.05)$ between cows in early and late lactation at any given time point. restriction were the best predictors of milk yield and DMI during restriction, respectively. Concentration of milk $B H B A_{\text {Before }}$, stage of lactation, and the interaction of $B H B A_{\text {Before }} \times$ stage of lactation were used in the final model as predictors of $B H B A_{\text {During }}\left(\mathrm{R}^{2}=0.67 ; P\right.$ $<0.001)$. The greater slope for cows in early lactation indicates that $B H B A_{\text {Before }}$ explains more variance in $B H B A_{\text {During }}$ for cows in early compared with cows in mid and late lactation. For changes in milk protein during restriction, the final model included Protein $_{\text {Before }}$, stage of lactation, and the interaction of $\operatorname{Protein}_{\text {Before }} \times$ stage of lactation $\left(\mathrm{R}^{2}=0.92 ; P<0.001\right)$. Predictions

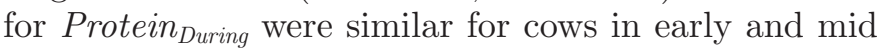
lactation, whereas Protein $n_{\text {Before }}$ was a better predictor of Protein $_{\text {During }}$ for cows in late lactation.

\section{DISCUSSION}

The development of metabolic diseases in the dairy industry is multifaceted, and the definition of PI by Ingvartsen (2006) assumes an association between PI and increased risk of disease for dairy cows throughout lactation. However, information on which physiological parameters should be included in a system to predict PI at different stages of lactation and production levels are lacking. This study increased PI via a dietary nutrient restriction that resulted in marked changes in metabolites in blood and liver as well as changes in production parameters. The results reported here (1) demonstrate that cows in early lactation use different coping strategies than cows in mid and late lactation in response to a dietary nutrient restriction; (2) identify several metabolites in blood (i.e., NEFA, BHBA, cholesterol, and glucose) that are associated with PI; and (3) reveal biological mechanisms potentially linked to the development of PI throughout lactation. The information reported here can be used to generate a system to predict PI with respect to which physiological parameters are relevant for the early detection of PI and consequently increased risk for certain diseases, such as ketosis and fatty liver.

Furthermore, this study identified milk citrate as a potential early indicator of PI in milk for on-farm warning systems throughout lactation. By $48 \mathrm{~h}$ of restriction, milk citrate had the greatest \%chg, regardless of stage of lactation. For cows in early lactation, milk citrate increased more rapidly than BHBA, and therefore, its use as an early indicator of PI and offfeed situations for on-farm systems warrants further investigation. Dietary nutrient restriction to $48 \%$ of $\mathrm{NE}_{\mathrm{L}}$ requirements decreased DMI by the same amount $(-10 \mathrm{~kg}$ of $\mathrm{DM})$, regardless of stage of lactation. Despite this, and despite the fact that daily milk yield was greater for cows in early than in mid or late lac- 
A

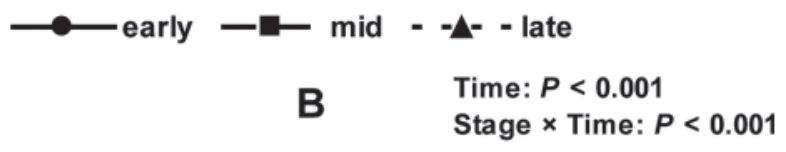

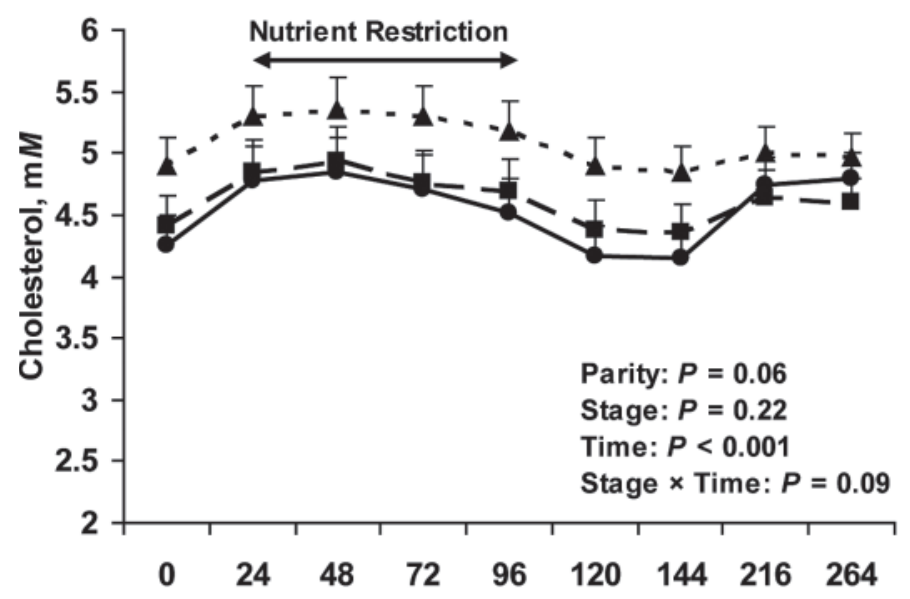

C

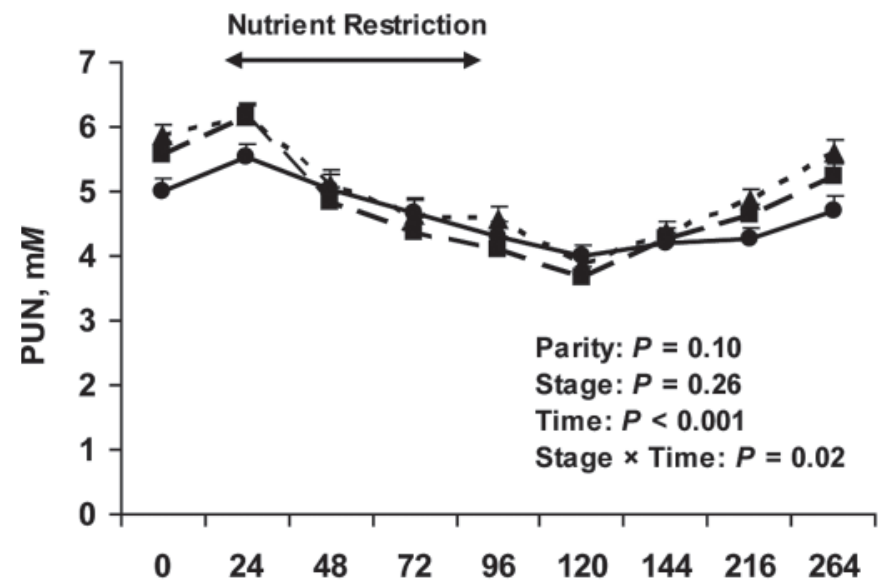

Time Relative to Nutrient Restriction (0-96 h)

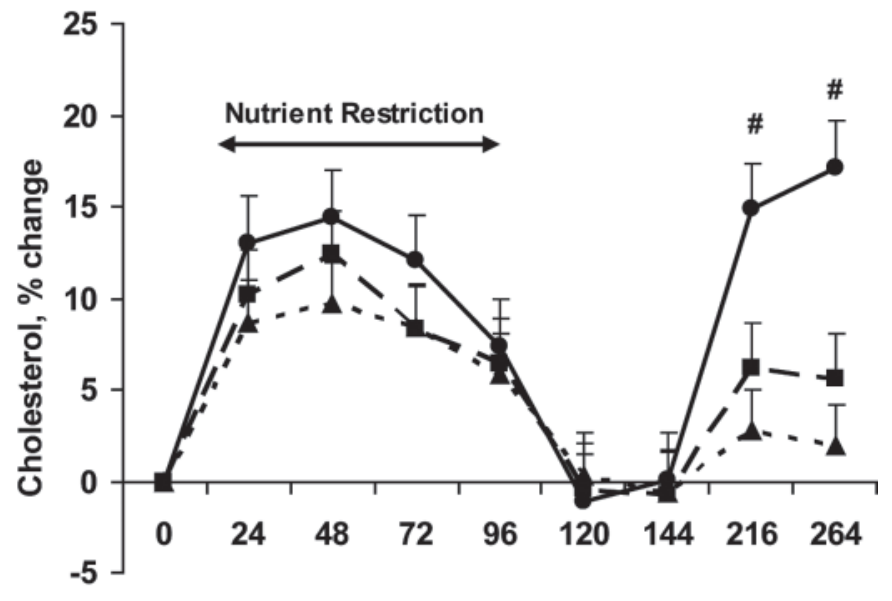

Time: $P<0.001$
Stage $\times$ Time: $P<0.001$

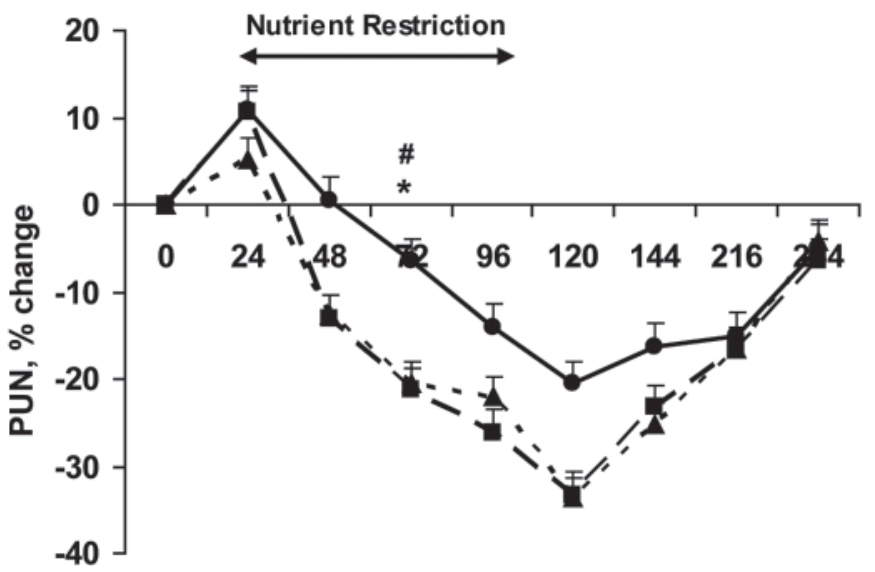

Time Relative to Nutrient Restriction (0-96 h)

Figure 5. Differences in plasma concentrations of cholesterol (A), percentage change in cholesterol (B), concentration of plasma urea nitrogen (PUN; C), and percentage change in PUN (D) at time points (i.e., hour) relative to dietary nutrient restriction (h $=0-96)$ in 47 Holstein cows in early $(\mathbf{\bullet})$, mid $(\boldsymbol{\square})$, and late $(\boldsymbol{\Delta})$ lactation. Time $=0$ reflects the average during an 8 -d adjustment period within stage of lactation. *Differences $(P<0.05)$ between cows in early and mid lactation at any given time point. \#Differences $(P<0.05)$ between cows in early and late lactation at any given time point.

tation throughout the study period, changes in daily milk yield were similar for all cows during restriction with an average proportional decrease of approximately $30 \%$ from pre-restriction values. This provides clear evidence of a homeorhetic influence on the adaptive response to reduction in dietary nutrient supply, because a $30 \%$ decrease in yield in early lactation represents a substantially greater decrease in amount of milk, and milk energy, than a $30 \%$ decrease in yield later in lactation. Regression analysis further supports these results indicating that milk yield before restriction (Table 3), rather than stage of lactation, is a major predictor of milk yield during restriction and that milk yield may partly contribute to the development of PI throughout lactation.

Cows in early lactation responded to nutrient restriction via a greater decrease in the \%chg in plasma glucose that, coupled with the pre-existing metabolic conditions stated above, led to increases in BHBA concentration compared with cows in mid and late lactation. Similar to results of others (Guinard-Flament et al., 2007; Moyes et al., 2009), short-term nutrient 

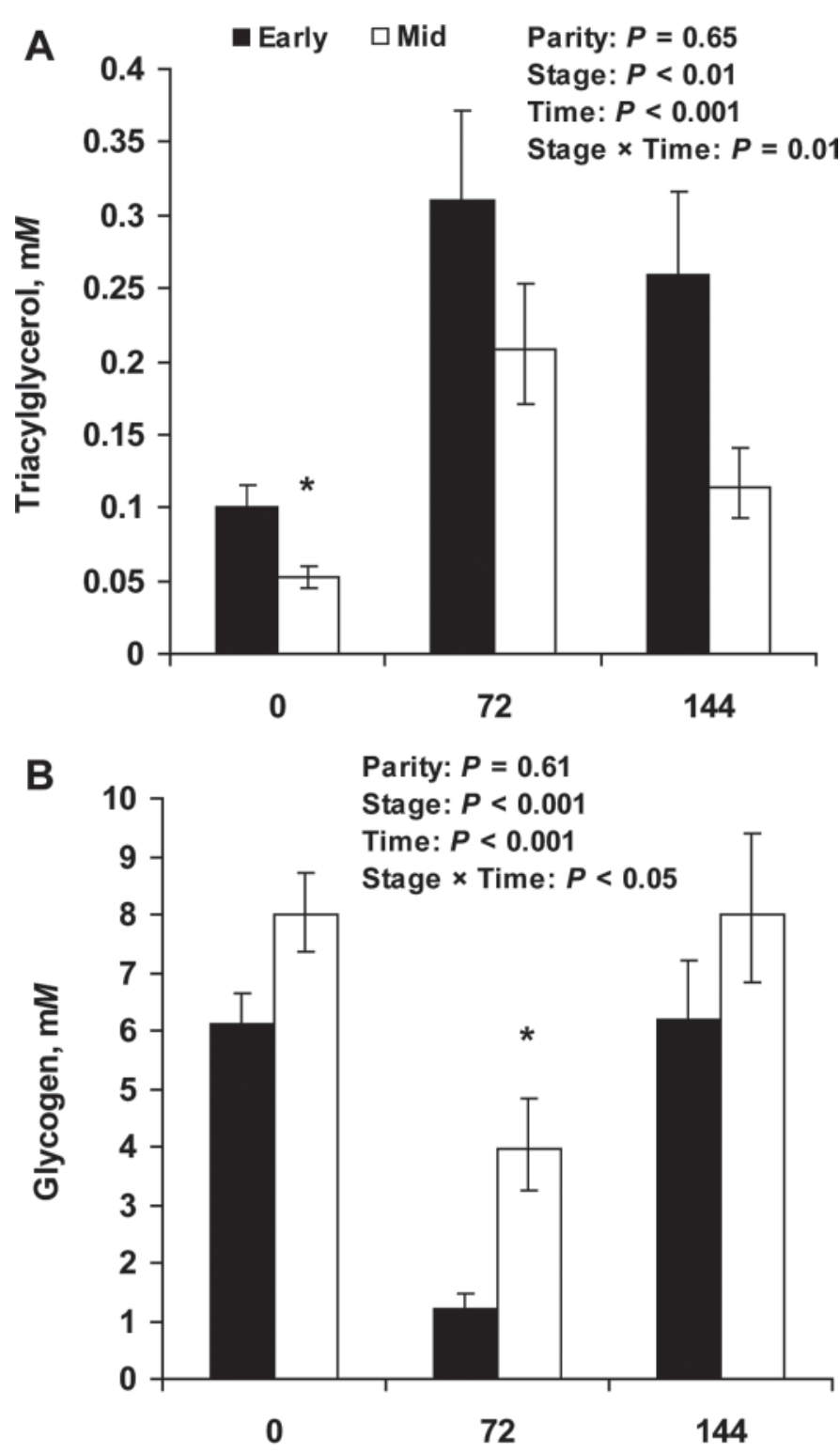

Time Relative to Nutrient Restriction (0-96 h)

Figure 6. Differences in content of liver triacylglycerol (A) and glycogen (B) at time points (i.e., hour) relative to dietary nutrient restriction $(\mathrm{h}=0-96)$ in 47 Holstein cows in early $(\bullet)$, mid $(\boldsymbol{\square})$, and late $(\boldsymbol{\Lambda})$ lactation. ${ }^{*}$ Differences $(P<0.05)$ between cows in early and mid lactation at any given time point.

restriction did not alter BHBA concentration for cows in mid and late lactation but plasma NEFA was greater for cows in mid and late lactation compared with cows in early lactation. This indicates that hepatic oxidation of body tissue energy, primarily in the form of NEFA mobilized from adipose tissue, was sufficient to meet the nutrient needs for cows in mid and late lactation. Regardless of stage of lactation, plasma cholesterol increased during restriction and may be partly attributed to the hepatic re-esterification of NEFA as TAG and its exportation into circulation within very low density lipoproteins (Smith et al., 1997; Drackley, 1999) and may be useful in an index for PI throughout lactation.

Interestingly, $7 \mathrm{~d}$ (i.e., $264 \mathrm{~h}$ relative to nutrient restriction) after cows returned to full feed, the \%chg in cholesterol was greater for cows in early than cows in mid and late lactation and absolute values increased above levels observed before restriction for early lactation cows only. However, absolute values of plasma cholesterol were similar among groups at this time. In addition to cholesterol, liver TAG content remained elevated for cows in early than in mid lactation during the recovery period. These results indicate that cows in early lactation do not recover as rapidly from a metabolic challenge compared with cows in later lactation and this response may be associated with the mechanisms controlling the partitioning of nutrients for lactation during periods of increased PI for cows in early lactation.

Increased insulin sensitivity was observed for cows in early lactation compared with cows in later lactation during a dietary challenge. In early lactation, the genetically driven negative energy balance (Friggens et al., 2007) observed at this time is associated with an insulin-resistant state in tissues such as adipose and skeletal muscle (Bauman, 2000; LeBlanc, 2010) to ensure that increased lipolytic responsiveness (Theilgaard et al., 2002) favors body lipid mobilization to supply an adequate amount of nutrients to the mammary gland (Bauman, 2000). Although a greater \%chg in glucose was observed for cows in early lactation, plasma insulin was similar among groups during restriction. Coupled with a higher G:I ratio during restriction, our results suggest an increase in insulin sensitivity for cows in early lactation during nutrient restriction. Furthermore, the \%chg in RQUICKI increased during restriction for cows in early lactation, whereas RQUICKI remained unchanged for cows in mid and late lactation. The RQUICKI, originally developed to measure insulin sensitivity in humans, is an assessment of energy balance based on plasma concentration of glucose, insulin, and NEFA and has been used to detect differences in insulin resistance in healthy, lactating dairy cows (Holtenius and Holtenius, 2007). However, Kerestes et al. (2009) observed that RQUICKI has a low discrimination power for decreased insulin sensitivity for cows with various metabolic disorders and suggest that it be applied with caution. Therefore, whether a true increase in insulin sensitivity was observed for cows in early compared with those in mid and late lactation is unknown. Further evaluation of RQUICKI and how it may contribute to our understanding of the metabolic 

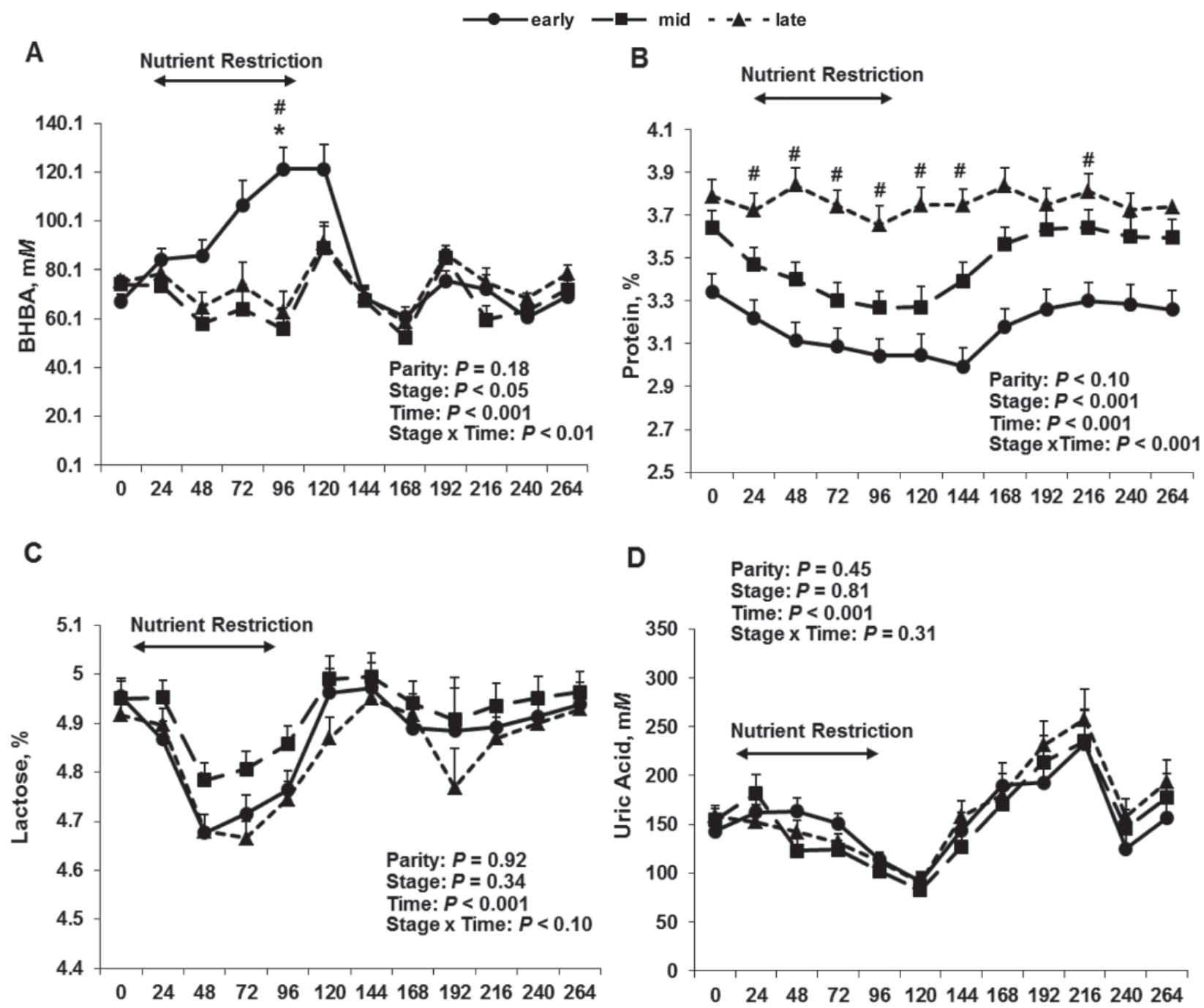

E

F
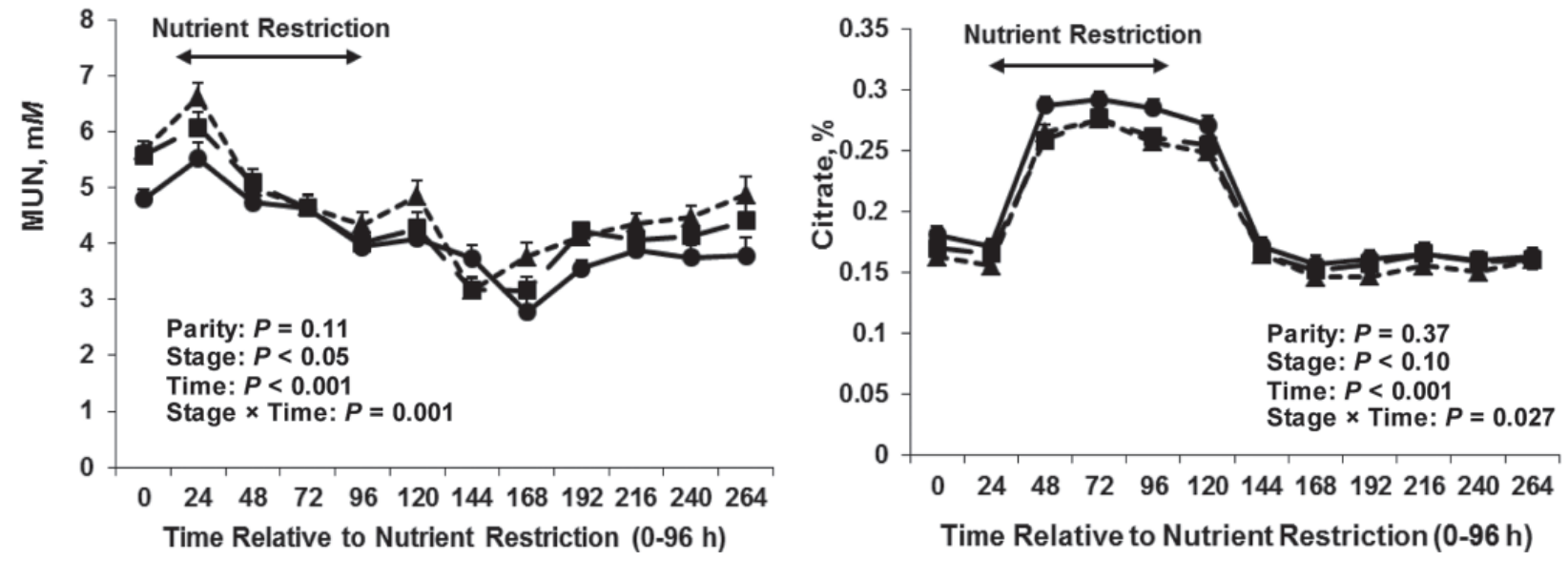

Time Relative to Nutrient Restriction $(0-96$ h)

Figure 7. Concentrations of milk BHBA (A), protein (B), lactose (C), uric acid (D), MUN (E), and citrate (F) at time points (i.e., hour) relative to dietary nutrient restriction $(\mathrm{h}=0-96)$ for 47 Holstein cows in early $(\bullet)$, mid $(\boldsymbol{\square})$, and late $(\mathbf{\Lambda})$ lactation. Time $=0$ reflects the average during an 8-d adjustment period within stage of lactation. *Differences $(P<0.05)$ between cows in early and mid lactation at any given time point. \#Differences $(P<0.05)$ between cows in early and late lactation at any given time point. 

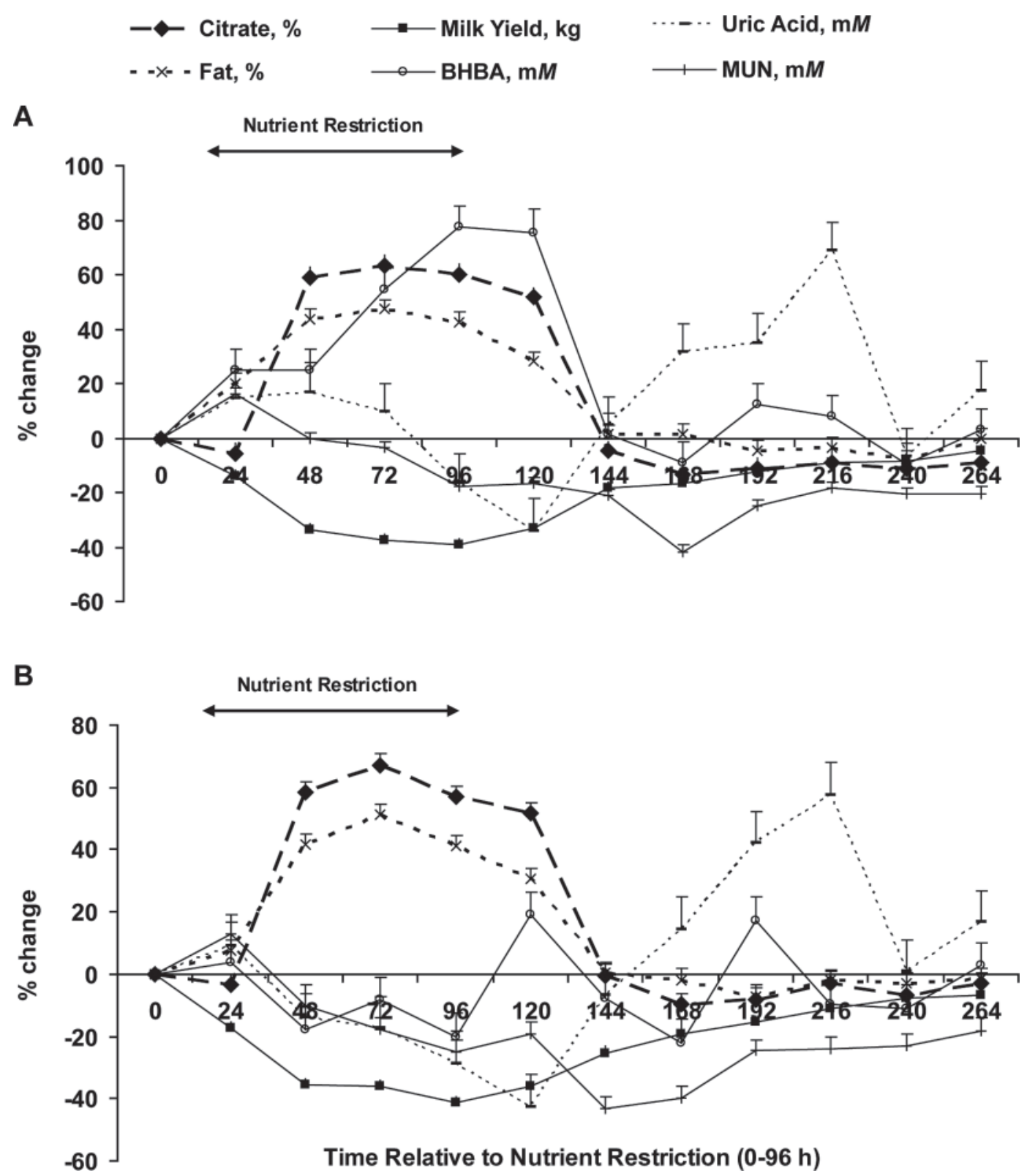

Figure 8. Percentage change in level of daily milk yield, BHBA, uric acid, citrate, fat, and MUN at time points (i.e., hour) relative to dietary nutrient restriction $(\mathrm{h}=0-96)$ for 47 Holstein cows in early $(\mathrm{A})$ and mid and late lactation $(\mathrm{B})$. Average change was calculated for cows in mid and late lactation because similar responses were observed.

response of cows at different physiological stages and the development of PI is warranted.

The effect of severity and duration of restriction on metabolic and production responses of cows during lactation has been documented (de Boer et al., 1985; Drackley et al., 1991) and is beyond the scope of this study. The severity and duration (i.e., short term) of the restriction for this study was designed to quantify abrupt changes in milk components that reflect the early development of PI and off-feed situations for cows throughout lactation. Results showed that milk yield before restriction is also a better predictor of DMI during restriction when compared with DIM (Table 3). Researchers have shown a strong relationship between milk yield and DMI and clinical signs of metabolic diseases, such as ketosis and fatty liver (Mills et al., 1986; Bobe et al., 2004; Ingvartsen, 2006), and this relationship further supports the links among milk yield, DMI, and the development of PI throughout lactation. In contrast, the regression analysis (Table 3 ) indicated 
Table 3. Linear regression model for DIM and daily milk yield before dietary nutrient restriction and the association with parameters during restriction

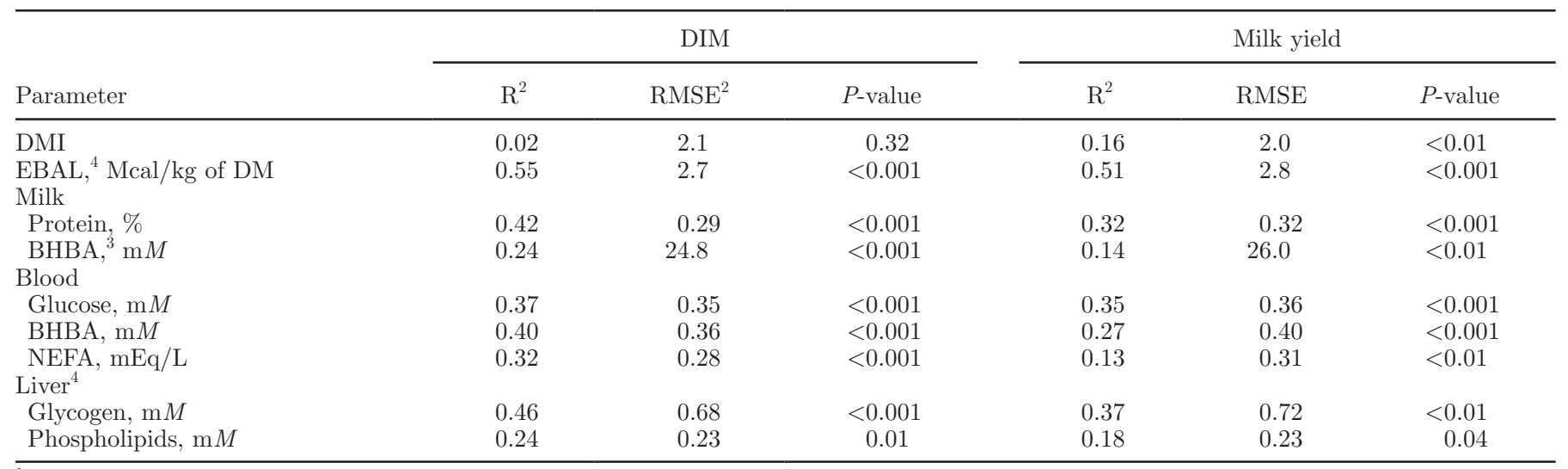

${ }^{1}$ Data are based on residuals generated using a general linear mixed model procedure of SAS Institute (2008) after adjustment for the effect of parity. Average residuals were then calculated for each cow within each period and used for the linear regression analysis. RMSE $=$ root mean square error of prediction.

${ }^{2} \mathrm{EBAL}=$ calculated energy balance based on NRC (2001) equations.

${ }^{3}$ Milk BHBA was calculated for cows in early lactation only.

${ }^{4}$ Liver samples were only collected from cows in early and mid lactation.

that DIM was a better indicator of changes in plasma NEFA, plasma and milk BHBA, and liver glycogen than average daily milk yield before restriction. Absolute changes in plasma glucose and BHBA during restriction are best predicted by stage of lactation when coupled with plasma concentration before restriction. We observed that early lactation was a better predictor than mid and late lactation with regard to changes in concentration of plasma glucose and BHBA during restriction (Table 4). Similar results were reported for milk BHBA (Table 5). This supports the use of BHBA relating to mobilization of body tissue as a biomarker for risk of ketosis (Nielsen et al., 2005) and its potential use in the development and detection of PI during early lactation. Our results show that plasma concentration of BHBA is negatively associated with plasma glucose. The individual variation of both metabolites might be a better predictor for the development and detection of PI rather than individual use. The generation of an index based on changes in blood glucose, BHBA, and other relevant metabolites (i.e., NEFA and cholesterol) and its use as a predictor for degree of PI and subsequent risk of disease (e.g., ketosis and fatty liver) are needed to link the degree of PI with specific biomarkers

Table 4. Parameter estimates and regression analysis information for the regression model selected to predict average level of plasma ln(NEFA; $\mathrm{mEq} / \mathrm{L}), \ln (\mathrm{BHBA} ; \mathrm{m} M)$, or glucose $(\mathrm{m} M)$ during dietary nutrient restriction ${ }^{1}$

\begin{tabular}{|c|c|c|c|c|c|c|c|c|c|}
\hline \multirow[b]{2}{*}{ Variable } & \multicolumn{3}{|c|}{$\ln (\mathrm{NEFA})_{\text {During }}{ }^{2}$} & \multicolumn{3}{|c|}{$\ln (\mathrm{BHBA})_{\text {During }}{ }^{3}$} & \multicolumn{3}{|c|}{ Glucose $_{\text {During }}{ }^{4}$} \\
\hline & Estimate & $\mathrm{SE}$ & $\operatorname{Pr}>|t|$ & Estimate & $\mathrm{SE}$ & $\operatorname{Pr}>|t|$ & Estimate & $\mathrm{SE}$ & $\operatorname{Pr}>|t|$ \\
\hline Early & - & - & - & 1.33 & 0.19 & 0.001 & -2.98 & 1.66 & 0.08 \\
\hline Mid & - & - & - & 0.18 & 0.21 & 0.41 & -1.04 & 2.17 & 0.63 \\
\hline Late & - & - & - & 0.0 & - & - & 0.0 & - & - \\
\hline Early & - & - & - & 1.61 & 0.39 & 0.001 & 0.64 & 0.41 & 0.13 \\
\hline Mid & - & - & - & 0.28 & 0.39 & 0.47 & 0.25 & 0.51 & 0.62 \\
\hline Late & - & - & - & 0.0 & - & - & 0.0 & - & - \\
\hline
\end{tabular}

${ }^{1}$ Level $_{\text {Before }}=$ average $\ln (\mathrm{NEFA}), \ln (\mathrm{BHBA})$, or glucose level in plasma before nutrient restriction; Level ${ }_{\text {During }}=$ average $\ln (\mathrm{NEFA}), \ln (\mathrm{BHBA})$, or glucose level in plasma during nutrient restriction; RMSE = root mean square error of prediction. Stage = stage of lactation for cows in early $(\mathrm{n}=14 ; 22-86 \mathrm{DIM})$, mid $(\mathrm{n}=15 ; 100-217 \mathrm{DIM})$, or late $(\mathrm{n}=18 ; 235-355$ DIM) lactation.

${ }^{2}$ Statistics related to the goodness of fit of the model for $\ln (\mathrm{NEFA})_{\text {During }}: \mathrm{R}^{2}=0.38, \operatorname{Pr}>|\mathrm{F}|=0.0001, \mathrm{n}=47, \mathrm{RMSE}=0.27$.

${ }^{3}$ Statistics related to the goodness of fit of the model for $\ln (\mathrm{BHBA})_{\text {During }}: \mathrm{R}^{2}=0.81$, $\operatorname{Pr}>|\mathrm{F}|=0.0001, \mathrm{n}=47, \mathrm{RMSE}=0.21$.

${ }^{4}$ Statistics related to the goodness of fit of the model for Glucose ${ }_{\text {During }}: \mathrm{R}^{2}=0.68$, $\operatorname{Pr}>|\mathrm{F}|=0.0001, \mathrm{n}=47, \mathrm{RMSE}=0.26$. 


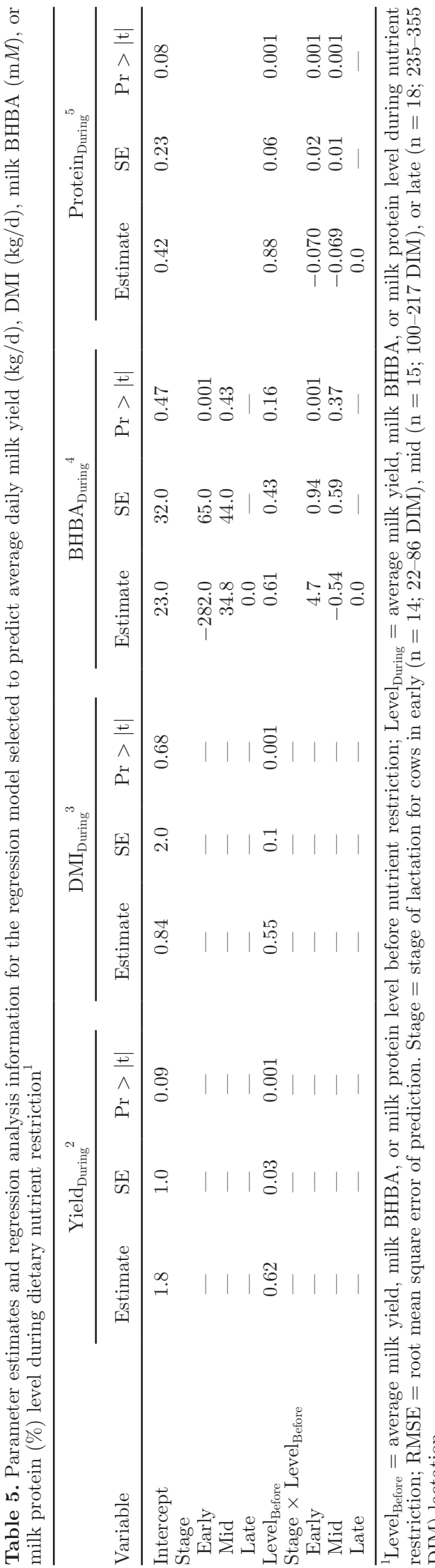

- $\stackrel{0}{\mathrm{I}}$ - $\mid$ $\|$ 오엉 됭

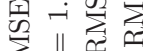
钫结

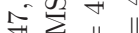
$\forall$ 更 $\|$ $\approx$ 占 당 $8=0$ $\dot{0} \dot{0} \|$ $\|$ \& 压压 压只我 $\wedge \| \dot{A}$

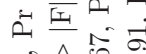

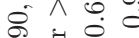
¿े

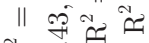
๘ै bo

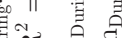
要 界

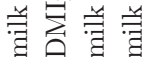

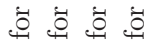
륭 $\overrightarrow{0}$ :

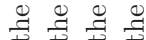

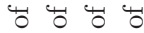
进荐范 岁岁㟧㟧 की की की ఫ्ञ 80 I I I 요요 㤩 $\frac{\pi}{0} \frac{\pi}{0} \frac{\pi}{0} \frac{\pi}{0}$

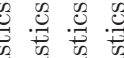

in more accessible samples (i.e., milk) for early on-farm warning systems.

One of the potential coping mechanisms observed by cows in early lactation for this study was an increased mammary uptake of plasma glucose for lactose synthesis. Plasma glucose was lower for cows in early lactation, whereas milk lactose concentrations were similar among groups. The mammary gland cannot synthesize glucose, and therefore, relies on circulating glucose for its requirements (Threadgold and Kuhn, 1979; Akers, 2002). Glucose is the main precursor for lactose synthesis in the mammary gland. Although mammary uptake of nutrients was not assessed for this study, results suggest an increased mammary uptake of plasma glucose for lactose synthesis in cows in early lactation. Milk lactose is the primary milk component that regulates milk volume via osmotic association (Guinard-Flament et al., 2006), which may explain the similar reductions in milk yield observed among treatment groups. Most importantly, our results identify a potential coping mechanism during dietary challenge for cows in early lactation compared with cows in later lactation. Individual differences in mammary uptake of plasma glucose, especially in early lactation, may provide information to explain the development of PI.

The metabolic status of cows in early lactation before restriction may partly explain the differences in response compared with cows in later lactation during restriction. Before restriction, cows in early lactation mobilized body tissue energy to support the energy required for lactation via higher plasma NEFA and liver TAG content and lower plasma glucose, which was not observed for cows in mid and late lactation; that is, when nutrient intake was sufficient to support milk production (Rastani et al., 2001; Baldwin et al., 2004). However, plasma and milk BHBA were not different among groups before restriction, indicating that the conversion of acetyl-CoA to ketone bodies was minimal and the capacity for complete hepatic $\beta$-oxidation of fatty acids was sufficient for cows in early lactation in this study. Regardless, the higher NEFA and liver TAG content and lower glucose observed before restriction partly explain the increase in plasma BHBA concentration during restriction for cows in early lactation.

During the recovery period, we observed an increase in milk UA for all cows, regardless of stage of lactation, and this may support the use of milk UA as a potential biomarker of rumen nitrogen flow and feed efficiency (Timmermans et al., 2000; Gonzalez-Ronquillo et al., 2003; Tas and Susenbeth, 2007). Milk yield has been postulated to be a factor that might influence the potential of UA in milk as a predictor of microbial protein passage in the duodenum (Tiemeyer et al., 1984). However, recent work in our laboratory indicated no corre- 
lation between milk yield and UA in milk (Larsen and Moyes, 2010). For this study, it is important to note that milk yield returned to pre-restriction levels during the recovery period for all cows, whereas milk UA increased above levels observed during the pre-restriction period. We conclude that milk yield plays a minor role, if any, in regard to milk UA and our results support the need for future studies examining the potential use of UA in milk as an indicator of rumen nitrogen flow and feed efficiency.

After $48 \mathrm{~h}$ of restriction, \%chg in citrate in milk was the greatest compared with all other milk components and indicated that citrate may be a useful indicator of PI and off-feed situations for early warning systems on-farm. Citrate has long been recognized as a constituent of milk that regulates the equilibrium between $\mathrm{Ca}^{2+}$ and $\mathrm{H}^{+}$ions (Faulkner and Peaker, 1982). For ruminants, acetate is the primary source of carbons for fat synthesis in the mammary gland and, in addition to the pentose phosphate pathway, the conversion of citrate to isocitrate, and its subsequent oxidation to $\alpha$-ketoglutarate, produces the reducing equivalent NADPH (Bauman et al., 1970). Therefore, increases in de novo synthesis of milk fat are characterized by decreases in concentration of citrate (Banks et al., 1984, 1990). It has also been suggested that citrate in milk is an indicator of energy status of the cow (Baticz et al., 2002) where citrate was negatively correlated to BHBA in milk from healthy cows. In contrast, periods of starvation have resulted in increased milk citrate and isocitrate concentration in association with increased rates of de novo milk fat synthesis in the mammary gland in lactating goats (Chaiyabutr et al., 1981).

Stage of lactation has been shown to alter concentrations of milk citrate. Milk citrate tends to be higher for cows in early than in mid lactation, primarily due to increased uptake of plasma NEFA into the mammary gland for milk fat synthesis during early lactation (Garnsworthy et al., 2006). For the present study, stage of lactation did not alter milk citrate concentration throughout the study period and may be attributed to the fact that cows in early lactation were $>21$ DIM, when plasma NEFA tend to be lower, compared with the early peripartal period (Rastani et al., 2001). Regardless, milk citrate may be a more useful indicator of early signs of PI and off-feed situations rather than fat content due to (1) the greater \%chg in milk citrate $(44.7 \%)$ compared with fat content (35.3\%) during restriction and (2) the low specificity of milk fat because it is has been shown to be positively associated with other common health disorders (Appuhamy et al., 2009; Moyes et al., 2009). Citrate, to our knowledge, has only been associated with mastitis, in which opposite patterns of change are observed when compared with PI; that is, decreases in milk citrate for cows with mastitis (Hyvönen et al., 2010). However, Sloth et al. (2003) observed no difference in milk citrate between cows with healthy and experimentally infected quarters. For cows in early lactation, milk BHBA increased by $25 \%$ during the first $24 \mathrm{~h}$ of restriction but did not peak $(77 \%)$ until $96 \mathrm{~h}$. Perhaps the combination of milk BHBA and citrate would be a good predictor of PI for cows in early lactation, but if we want indicators that are more robust and can be utilized throughout lactation, citrate would be of greater value.

\section{CONCLUSIONS}

This study quantified the differences in the metabolic and production responses of cows in PI at different stages of lactation. Stage of lactation did not alter changes in milk lactose during restriction and may partly explain the similar proportional decreases in milk yield during restriction among cows at different stages of lactation. The similar milk yield response throughout lactation indicates that the capacity of individual responses of cows during a dietary challenge is dependent on milk yield but the coping strategies used by cows are dependent on stage of lactation. This is supported by the regression analysis that showed milk yield before restriction, rather than DIM, is the best predictor of both milk yield and DMI during restriction. The increase in RQUICKI value for cows in early lactation indicates heightened insulin sensitivity during restriction. Results reported here identified the major metabolites (i.e., glucose, NEFA, BHBA, and cholesterol) to be included in an index to predict PI and milk citrate as a promising biomarker for PI for in-line and real-time early warning systems to prevent and reduce the incidence of disease. Further examination of their use as indicators of PI is necessary to develop new management strategies that efficiently prevent diseases and improve welfare and productivity and economic outcome of the farmer.

\section{ACKNOWLEDGMENTS}

This work was supported by the Danish National Advanced Technology Foundation (Copenhagen, Denmark), Lattec I/S (Hillerød, Denmark), Danish Cattle Federation (Aarhus, Denmark), the Milk Levy Fund (c/o the Danish Dairy Board, Aarhus, Denmark), and the Danish Ministry of Food, Agriculture and Fisheries (Copenhagen, Denmark). Furthermore, we thank J. B. Clausen, H. Sejersen, and C. Bertelsen (Department of Animal Science, Aarhus University) for their skillful help during sampling and analysis of samples. 


\section{REFERENCES}

Akers, R. M. 2002. Lactation and the Mammary Gland. Iowa State Press, Ames.

Andersen, J. B., D. G. Mashek, T. Larsen, M. O. Nielsen, and K. L. Ingvartsen. 2002. Effects of hyperinsulinaemia under euglycaemic condition on liver fat metabolism in dairy cows in early and mid lactation. J. Vet. Med. A Physiol. Pathol. Clin. Med. 49:65-71.

Anonymous. 1992. Manual for the Requisition of Chemical Analysis. Danish Institute of Agricultural Sciences, Tjele, Denmark.

Appuhamy, J. A., B. G. Cassell, and J. B. Cole. 2009. Phenotypic and genetic relationships of common health disorders with milk and fat yield persistencies from producer-recorded health data and testday yields. J. Dairy Sci. 92:1785-1795.

Baldwin, R. L., K. R. McLeod, and A. V. Capuco. 2004. Visceral tissue growth and proliferation during the bovine lactation cycle. J. Dairy Sci. 87:2977-2986.

Banks, W., J. L. Clapperton, and A. K. Girdler. 1990. Effect of dietary unsaturated fatty acids in various forms on the de novo synthesis of fatty acids in the bovine mammary gland. J. Dairy Res. 57:179-185.

Banks, W., J. L. Clapperton, A. K. Girdler, and W. Steele. 1984. Effect of inclusion of different forms of dietary fatty acid on the yield and composition of cow's milk. J. Dairy Res. 51:387-395.

Baticz, O., S. Tomoskozi, L. Vida, and T. Gaal. 2002. Relationship between concentration of citrate and ketone bodies in cow's milk. Acta Vet. Hung. 50:253-261.

Bauman, D. E. 2000. Regulation of nutrient partitioning during lactation: Homeostasis and homeorhesis revisited. Pages 311-328 in Ruminant Physiology: Digestion, Metabolism, Growth and Reproduction. P. B. Cronje, ed. CABI Publishing, New York, NY.

Bauman, D. E., R. E. Brown, and C. L. Davis. 1970. Pathways of fatty acid synthesis and reducing equivalent generation in mammary gland of rat, sow, and cow. Arch. Biochem. Biophys. 140:237-244.

Bobe, G., J. W. Young, and D. C. Beitz. 2004. Invited review: Pathology, etiology, prevention, and treatment of fatty liver in dairy cows. J. Dairy Sci. 87:3105-3124.

Chaiyabutr, N., A. Faulkner, and M. Peaker. 1981. Changes in the concentrations of the minor constituents of goat's milk during starvation and on refeeding of the lactating animal and their relationship to mammary gland metabolism. Br. J. Nutr. 45:149-157.

Chapinal, N., D. M. Veira, D. M. Weary, and M. A. von Keyserlingk. 2007. Technical note: Validation of a system for monitoring individual feeding and drinking behavior and intake in group-housed cattle. J. Dairy Sci. 90:5732-5736.

de Boer, G., A. Trenkle, and J. W. Young. 1985. Glucagon, insulin, growth hormone, and some blood metabolites during energy restriction ketonemia of lactating cows. J. Dairy Sci. 68:326-337.

Drackley, J. K. 1999. Biology of dairy cows during the transition period: The final frontier? J. Dairy Sci. 82:2259-2273.

Drackley, J. K., J. J. Veenhuizen, M. J. Richard, and J. W. Young. 1991. Metabolic changes in blood and liver of dairy cows during either feed restriction or administration of 1,3-butanediol. J. Dairy Sci. $74: 4254-4264$.

Faulkner, A., and M. Peaker. 1982. Reviews of the progress of dairy science: Secretion of citrate into milk. J. Dairy Res. 49:159-169.

Folch, J., M. Lees, and G. H. S. Stanley. 1957. A simple method for the isolation and purification of total lipids from animal tissues. J. Biol. Chem. 226:497-509.

Friggens, N. C., P. Berg, P. Theilgaard, I. R. Korsgaard, K. L. Ingvartsen, P. Lovendahl, and J. Jensen. 2007. Breed and parity effects on energy balance profiles through lactation: Evidence of genetically driven body energy change. J. Dairy Sci. 90:5291-5305.

Garnsworthy, P. C., L. L. Masson, A. L. Lock, and T. T. Mottram. 2006. Variation of milk citrate with stage of lactation and de novo fatty acid synthesis in dairy cows. J. Dairy Sci. 89:1604-1612.

Gonzalez-Ronquillo, M., J. Balcells, J. A. Guada, and F. Vicente. 2003. Purine derivative excretion in dairy cows: Endogenous excretion and the effect of exogenous nucleic acid supply. J. Dairy Sci. $86: 1282-1291$.
Guinard-Flament, J., E. Delamaire, P. Lamberton, and J. L. Peyraud. 2007. Adaptations of mammary uptake and nutrient use to oncedaily milking and feed restriction in dairy cows. J. Dairy Sci. 90:5062-5072

Guinard-Flament, J., E. Delamaire, S. Lemosquet, M. Boutinaud, and Y. David. 2006. Changes in mammary uptake and metabolic fate of glucose with once-daily milking and feed restriction in dairy cows. Reprod. Nutr. Dev. 46:589-598.

Harano, Y., M. Ohtsuki, M. Ida, H. Kojima, M. Harada, T. Okanishi, A. Kashiwagi, Y. Ochi, S. Uno, and Y. Shigeta. 1985. Direct automated assay method for serum or urine levels of ketone bodies. Clin. Chim. Acta 151:177-183.

Holtenius, P., and K. Holtenius. 2007. A model to estimate insulin sensitivity in dairy cows. Acta Vet. Scand. 49:29-31.

Hyvönen, P., T. Haarahiltunen, T. Lehtolainen, J. Heikkinen, R. Isomäki, and S. Pyörälä. 2010. Concentrations of bovine lactoferrin and citrate in milk during experimental endotoxin mastitis in early- versus late-lactating dairy cows. J. Dairy Res. 77:474-480.

Ingvartsen, K. L. 2006. Feeding- and management-related diseases in the transition cow, physiological adaptions around calving and strategies to reduce feeding-related diseases. Anim. Feed Sci. Technol. 126:175-213.

Ingvartsen, K. L., and J. B. Andersen. 2000. Integration of metabolism and intake regulation: A review focusing on periparturient animals. J. Dairy Sci. 83:1573-1597.

Ingvartsen, K. L., and N. C. Friggens. 2005. To what extent do variabilities in hormones, metabolites and energy intake explain variability in milk yield? Domest. Anim. Endocrinol. 29:294-304.

Kerestes, M., V. Faigl, M. Kulcsar, O. Balogh, J. Foldi, H. Febel, Y Chilliard, and G. Huszenicza. 2009. Periparturient insulin secretion and whole-body insulin responsiveness in dairy cows showing various forms of ketone pattern with or without puerperal metritis. Domest. Anim. Endocrinol. 37:250-261.

Larsen, T., and K. M. Moyes. 2010. Fluorometric determination of uric acid in bovine milk. J. Dairy Res. 77:438-444.

Larsen, T., and N. I. Nielsen. 2005. Fluorometric determination of $\beta$-hydroxybutyrate in milk and blood plasma. J. Dairy Sci. 88:2004-2009.

Larsen, T., C. M. Røntved, K. L. Ingvartsen, L. Vels, and M. Bjerring. 2010. Enzyme activity and acute phase proteins in milk utilized as indicators of acute clinical E. coli LPS-induced mastitis. Animal 4:1672-1679.

LeBlanc, S. 2010. Monitoring metabolic health of dairy cattle in the transition period. J. Reprod. Dev. 56(Suppl.):S29-S35.

Løvendahl, P., and H. M. Purup. 2002. Technical note: Time-resolved fluoro-immunometric assay for intact insulin in livestock species. J. Anim. Sci. 80:191-195.

Mills, S. E., D. C. Beitz, and J. W. Young. 1986. Characterization of metabolic changes during a protocol for inducing lactation ketosis in dairy cows. J. Dairy Sci. 69:352-361.

Moyes, K. M., J. K. Drackley, J. L. Salak-Johnson, D. E. Morin, J. C. Hope, and J. J. Loor. 2009. Dietary-induced negative energy balance has minimal effects on innate immunity during a Streptococcus uberis mastitis challenge in dairy cows during mid lactation. J. Dairy Sci. 92:4301-4316.

Moyes, K. M., N. C. Friggens, and K. L. Ingvartsen. 2010. Nutritional strategies to combat physiological imbalance of dairy cows during early lactation: The effect of changes in dietary protein and starch ratios. Acta Vet. Scand. A 60:166-174.

National Research Council. 2001. Nutrient Requirements of Dairy Cattle. National Academy Press, Washington, DC.

Nielsen, N. I., N. C. Friggens, M. G. Chagunda, and K. L. Ingvartsen. 2005. Predicting risk of ketosis in dairy cows using in-line measurements of $\beta$-hydroxybutyrate: A biological model. J. Dairy Sci. 88:2441-2453.

Olishevsky, S., A. Burlaka, E. Sidorik, V. Shlyakhovenko, Y. Garpenko, and V. Kozak. 2006. Modulation of ROS/NO production by murine peritoneal macrophages in response to bacterial CpG DNA stimulation. Exp. Oncol. 28:114-120.

Radcliff, R. P., B. L. McCormack, D. H. Keisler, B. A. Crooker, and M. C. Lucy. 2006. Partial feed restriction decreases growth hor- 
mone receptor 1A mRNA expression in postpartum dairy cows. J. Dairy Sci. 89:611-619.

Rastani, R. R., S. M. Andrew, S. A. Zinn, and C. J. Sniffen. 2001. Body composition and estimated tissue energy balance in Jersey and Holstein cows during early lactation. J. Dairy Sci. 84:12011209.

SAS Institute. 2008. User's Guide: Statistics. Version 9, 2nd ed. SAS Institute Inc., Cary, NC.

Sloth, K. H., N. C. Friggens, P. Lovendahl, P. H. Andersen, J. Jensen, and K. L. Ingvartsen. 2003. Potential for improving description of bovine udder health status by combined analysis of milk parameters. J. Dairy Sci. 86:1221-1232.

Smith, T. R., A. R. Hippen, D. C. Beitz, and J. W. Young. 1997. Metabolic characteristics of induced ketosis in normal and obese dairy cows. J. Dairy Sci. 80:1569-1581.

Starke, A., S. Schmidt, A. Haudum, T. Scholbach, P. Wohlsein, M. Beyerbach, and J. Rehage. 2011. Evaluation of portal blood flow using transcutaneous and intraoperative Doppler ultrasonography in dairy cows with fatty liver. J. Dairy Sci. 94:2964-2971.
Tas, B., and A. Susenbeth. 2007. Urinary purine derivatives excretion as an indicator of in vivo microbial $\mathrm{N}$ flow in cattle: A review. Livest. Prod. Sci. 111:181-192.

Theilgaard, P., N. C. Friggens, K. H. Sloth, and K. L. Ingvartsen. 2002. The effect of breed, parity and body fatness on the lipolytic response of dairy cows. Anim. Sci. 75:209-219.

Threadgold, L. C., and N. J. Kuhn. 1979. Glucose-6-phosphate hydrolysis by lactating rat mammary gland. Int. J. Biochem. 10:683685.

Tiemeyer, W., M. Stohrer, and D. Giesecke. 1984. Metabolites of nucleic acids in bovine milk. J. Dairy Sci. 67:723-728.

Timmermans, S. J., L. M. Johnson, J. H. Harrison, and D. Davidson. 2000. Estimation of the flow of microbial nitrogen to the duodenum using milk uric acid or allantoin. J. Dairy Sci. 83:1286-1299. Vasquez-Añon, M., S. Bertics, M. Luck, R. R. Grummer, and J. Pinheiro. 1994. Peripartum liver triglyceride and plasma metabolites in dairy cows. J. Dairy Sci. 77:1521-1528. 